\title{
Biosynthesis and Role of N-Linked Glycosylation in Cell Surface Structures of Archaea with a Focus on Flagella and S Layers
}

\author{
Ken F. Jarrell, Gareth M. Jones, and Divya B. Nair \\ Department of Microbiology and Immunology, Queen's University, Kingston, ON, Canada K7L 3N6 \\ Correspondence should be addressed to Ken F. Jarrell, jarrellk@queensu.ca
}

Received 9 March 2010; Accepted 1 August 2010

Academic Editor: Charlene Kahler

Copyright () 2010 Ken F. Jarrell et al. This is an open access article distributed under the Creative Commons Attribution License, which permits unrestricted use, distribution, and reproduction in any medium, provided the original work is properly cited.

The genetics and biochemistry of the N-linked glycosylation system of Archaea have been investigated over the past 5 years using flagellins and S layers as reporter proteins in the model organisms, Methanococcus voltae, Methanococcus maripaludis, and Haloferax volcanii. Structures of archaeal $\mathrm{N}$-linked glycans have indicated a variety of linking sugars as well as unique sugar components. In M. voltae, M. maripaludis, and H. volcanii, a number of archaeal glycosylation genes ( $a g l)$ have been identified by deletion and complementation studies. These include many of the glycosyltransferases and the oligosaccharyltransferase needed to assemble the glycans as well as some of the genes encoding enzymes required for the biosynthesis of the sugars themselves. The N-linked glycosylation system is not essential for any of M. voltae, M. maripaludis, or H. volcanii, as demonstrated by the successful isolation of mutants carrying deletions in the oligosaccharyltransferase gene aglB (a homologue of the eukaryotic Stt3 subunit of the oligosaccharyltransferase complex). However, mutations that affect the glycan structure have serious effects on both flagellation and S layer function.

\section{Introduction}

$\mathrm{N}$-linked glycosylation is one of the most common posttranslational modifications found on proteins in eukaryotic cells [1] and has now been documented in both prokaryotic domains as well $[2,3]$. Searches of complete genome sequences can readily identify homologues to the oligosaccharyltransferase STT3 subunit that transfers the assembled glycan from a lipid carrier to the target motif (amide linkage to asparagine within the sequon N-X-S/T) on the protein. This gene would be required in all organisms where N-linked glycosylation occurs and is readily found in eukarya and a limited number of bacteria but in almost all sequenced archaeal genomes. Of greater than 50 completed archaeal genomes, only 2 appear to lack this gene (Aeropyrum pernix and Methanopyrus kandleri) [4], suggesting that this posttranslational modification is much more common in archaea than in bacteria. Indeed, while many glycans associated with $\mathrm{S}$ layers in Bacteria have been reported, all are exclusively O-linked [5]. In Archaea, where glycosylation of S layers is more common than in Bacteria, most glycan linkages are of the $\mathrm{N}$ variety [6], although $\mathrm{S}$ layers containing glycans attached by both $\mathrm{O}$ and $\mathrm{N}$ linkage occur [7]. Extremely little is known of the O-linked process in Archaea.

In Archaea, N-linked glycosylation is most commonly found on S layer proteins $[3,6,8-12]$ and flagellins [7, 9, $10,13,14]$ and, more recently, on another surface protein, pilin (unpublished data). However, there are other proteins that have been shown in a variety of archaeal species to be N-glycosylated that are unrelated to those commonly $\mathrm{N}$-glycosylated proteins. These include a hexasaccharidemodified cytochrome $b_{558-566}$ in Sulfolobus acidocaldarius [15] and a cytoplasmic membrane protein in Thermoplasma acidophilum containing a highly branched glycan, composed mainly of mannose that is N-linked through an $\mathrm{N}$-acetylglucosamine [16]. In addition, it was shown in Pyrococcus furiosus that purified oligosaccharyltransferase could transfer a lipid-linked heptasaccharide prepared from P. furiosus cells to an Asn within a sequon Asn-X-Thr/Ser contained in a peptide substrate [17]. The role that the $\mathrm{N}$-linked glycan plays is uncertain but what is known is that underglycosylation or nonglycosylation of these proteins can have significant effects (see below), even though for Methanococcus voltae, Methanococcus maripaludis, and 
Haloferax volcanii, knockouts of the oligosaccharyltransferase have been reported [18-20] indicating that the Nlinked process is not an essential one for either of these model archaea.

In this contribution, $\mathrm{N}$-linked glycosylation structures, assembly, biosynthesis, and role in archaeal surface structures are reviewed.

\section{Surface Appendages in Archaea}

Similar to bacteria, the existence of surface appendages on archaeal cells has been known for a long time [21-23]. Some structures, like archaeal flagella and pili, show similarities to their bacterial counterparts in appearance, while several other structures like cannulae, hami, the newly discovered Ignicoccus fibers [24], and the putative bindosome appear to be novel structures found, thus far, only on archaeal cells [23].

2.1. Flagella. Archaeal flagella are rotating organelles with a filament and hook as seen in bacteria, but they do not show any similarity to the bacterial flagella in terms of their component parts or assembly [25-29]. The flagella of archaea are often in the $10-12 \mathrm{~nm}$ diameter range, much thinner than typical bacterial flagellar diameters. The flagellin structural proteins are typically 200-240 amino acids long, although there are some significantly longer. Archaeal flagella, the most thoroughly studied of the archaeal appendages, are only swimming, but also involved in cell-cell interactions and in the initial attachment to surfaces as a prerequisite for biofilm initiation in certain archaea $[30,31]$.

Flagella have been reported in all of the major subgroupings of cultivatable archaea, such as halophiles, haloalkaliphiles, methanogens, hyperthermophiles, and thermoacidophiles [27, 32]. Detailed studies have been reported in a variety of archaeal genera, including Methanococcus [33, 34], Halobacterium [35-37], Sulfolobus [38], Natrialba [39], Thermococcus [40], and Pyrococcus [30]. Even though they are superficially similar to bacterial flagella in appearance, the archaeal flagellum is a unique motility apparatus that has a well documented similarity to bacterial type IV pili $[32,41-$ 44]. These similarities include structural ones as well as the presence of a number of genes that are conserved between the two systems. Early observations indicated a sequence similarity of archaeal flagellins and type IV pilins at their N-termini [45] and the presence of type IV pilin-like signal peptides on archaeal flagellins [33, 46, 47]. Later studies revealed conserved proteins in both systems, including an ATPase [48], a conserved membrane protein [49], and a signal peptidase (FlaK/PibD) $[46,47,50,51]$.

Flagellated archaea generally possess a single major identified genetic locus which encodes the flagellins and a number of conserved fla genes, including flaH, flaI, and flaJ that are found in all flagellated archaea. Between the flagellin genes and flaHIJ can be a variable number of other genes from among flaC, D, E, F, and G. Genetic studies have shown that these genes, as well as the conserved flaHIJ, are essential for flagella assembly even though not all flagellated archaea possess them [52-55]. FlaI, a homologue of the extension and retraction ATPases in the type IV pili systems, has been shown to display ATPase activity [56] and exist as a hexamer [57]. FlaH is another possible ATPase: it contains a Walker Box A but not a Walker Box B [58] but no studies on its possible ATPase activity have been reported. FlaJ is similar to the conserved type IV pilus system membrane component PilC/TadB and may form part of the platform for assembly of the flagella $[49,59]$. An additional genetic similarity to the type IV pili system is the presence of a prepilin peptidase homologue gene, the preflagellin peptidase $f l a K / p i b D$, usually located elsewhere on the chromosome from the main fla operon, which encodes an essential signal peptidase required for flagellin processing. It is a member of the same novel aspartic acid protease family of enzymes as the prepilin peptidase.

While numerous similarities of archaeal flagella to type IV pili have been presented, other fundamental differences that clearly differentiate archaeal from bacterial flagella have been identified. Recently, it was shown that the rotation of archaeal flagella is powered by ATP hydrolysis and not by the proton motive or sodium motive force used by bacterial flagella [60]. In addition, a key structural feature that makes the archaeal flagellum unique is the lack of a central channel $[43,44]$. Hence, it was clear that the assembly of the archaeal flagella could not take place by addition of flagellin subunits traveling from the base through the hollow structure to final incorporation at the distal tip, as seen in the well-studied type III secretion system used for assembly of bacterial flagella [61] but most likely occurred by subunits added at the base $[26,32]$. See below (model of assembly of archaeal glycosylated flagellins into flagellar filaments) for more on assembly of archaeal flagella.

Glycosylation of archaeal flagellins appears to be a widespread posttranslational modification [62]. Unlike the case of bacterial flagellins where there are occasional reports of flagellin glycoproteins but always with an O-linked glycan [63], archaeal flagellins are modified with an Nlinked glycan. A three- or four-sugar glycan has been reported on Methanococcus flagellins $[9,13,64]$ and this glycan attachment has profound effects on the assembly and functioning of the flagella (see below).

2.2. Pili. Pili are among the most common surface appendages found on archaeal species and have been reported for decades $[21,22]$. However, there is still only limited information available on these appendages although structural, functional, and genetic studies have recently been published on pili from several archaeal species. At least two different types of pili structures have been reported in Archaea: ones that are assembled from type IV pilin-like proteins, as seen in several genera including Methanococcus and Sulfolobus, and pili that are not seemingly related to type IV pili, as in Methanothermobacter thermoautotrophicus. A study on $M$. thermoautotrophicus fimbriae/pili indicated that the main structural component was a $16 \mathrm{kDa}$ glycoprotein (Mth60) with no known homologues reported in the databases [65]. For the first time in Archaea, pili structures were shown to be adhesive surface appendages, and their abundance on the 
cell surface was greatly enhanced when cells were grown on surfaces rather than in liquid cultures [65].

Recent studies on S. solfataricus have reported that a type IV pilus-like operon, including an ATPase, membrane component, and two pilin-like genes was strongly upregulated upon UV light irradiation [66, 67]. Pili-like structures termed Ups pili, $10 \mathrm{~nm}$ in diameter and peritrichously located on the cell surface, were found following UV treatment, and these pili were necessary for a subsequent cellular aggregation which may enhance DNA transfer, helping cells recover from UV induced DNA damage [67]. Deletion of the ATPase found in the pilin operon leads to nonpiliated cells, confirming that this locus was responsible for the observed Ups pili [67]. Ups pili were also shown to be essential, along with flagella, for initial attachment to surfaces, and upregulation of genes involved in pili formation was demonstrated upon attachment of cells [31].

Pili on the surface of $M$. maripaludis are much less numerous than flagella. Pili from M. maripaludis are composed of a major structural protein of $17 \mathrm{kDa}$. Using cryoelectron microscopy, it was shown that these pili have a structure unlike that of any known bacterial pili, with two subunit packing arrangements coexisting within the same pilus [68]. A genetic locus, predicted to be involved in type IV pili-like structures, was identified [69], and subsequent genetic knockout work has confirmed their involvement with pili formation, although the apparent major structural pilin is encoded outside this locus and is only 62-amino acid long after signal peptide removal (unpublished results). This locus is also unusual in that the assembly ATPase is not located there but is instead located elsewhere on the chromosome (unpublished results). The locus contains 3 pilin-like genes and an associated prepilin-like peptidase, EppA. All prepilins are potentially glycoproteins, with the major structural pilin proven to have an $\mathrm{N}$-linked glycan similar to the one found on flagellins but unexpectedly with an additional, branched sugar (unpublished results). It was shown in coexpression studies that EppA was able to process the prepilins but not the preflagellins while the preflagellin peptidase FlaK was able to process preflagellins but not the prepilins, even though both precursors have type IV prepilinlike signal peptides and the amino acids surrounding the cleavage site are quite similar [69]. Interestingly, in Sulfolobus a single prepilin peptidase-like enzyme, $\mathrm{PibD}$, processes the flagellins, pilins, and sugar-binding proteins and has been demonstrated to have a less restrictive requirement for its substrates than FlaK $[50,70]$.

As more archaeal species are examined in detail, it seems inevitable that additional fundamentally different types of pili will be discovered, as has been demonstrated already in bacteria.

\subsection{Cannulae, Hami, Iho670 Fibers, and the Bindosome.} Other surface structures have been reported in Archaea, although they are currently not as well studied as flagella and pili, often because they are found in species without tractable genetic systems. One such surface structure is a network of tubules, termed cannulae, which have only been found so far in the genus Pyrodictium. Cannulae are hollow tubes that are highly resistant to heat and denaturing agents [71]. As with many archaeal surface structures, they are composed of glycoproteins, in this case three homologous glycoprotein subunits, although the nature of the glycan linkage has not been reported. Evidence has shown that cannulae act as an intercellular connector of periplasmic spaces between different cells [72]. Although the precise function of cannulae is unknown, it is assumed that they anchor cells to each other and they may be involved in the exchange of nutrients or even genetic material between cells.

Another appendage, recently reported in a formally undescribed archaeon isolated from a cold sulfidic spring, is the novel filamentous structure termed the hamus. Hami are appendages of remarkably high complexity with the appearance of barbed wire ending in a grappling hook $60 \mathrm{~nm}$ in diameter [73]. Each cell is surrounded by about 100 hami. Hami are stable over a wide temperature range $(0$ to $70^{\circ} \mathrm{C}$ ) and $\mathrm{pH}$ range (0.5 to 11.5$)$ and are composed of subunits of $120 \mathrm{kDa}$ that did not stain with the glycoproteinstaining periodic acid Schiff (PAS) reagent. They mediate strong cellular adhesion to surfaces of different chemical compositions as well as adhesion between cells themselves. Hami were also shown to be the major protein component of an archaeal biofilm, where cells form a regular threedimensional arrangement kept a constant distance apart from each other, likely through the activity of the hami [74].

The bindosome is a putative archaeal structure with a unique function in S. solfataricus [75]. The main structural components of the bindosome are substrate (sugar) binding proteins made with type IV pilin-like signal peptides that are cleaved by the same prepilin peptidase homologue (PibD) that removes the signal peptides from both flagellins and pilins in this organism. Hence, the bindosome has been proposed to be a pilus-like structure located near the surface of the cell [76]. Consistent with many other archaeal surface structures, the substrate binding proteins are known to be glycoproteins [77]. Among the sugars identified in the glycan was $\mathrm{N}$-acetylglucosamine, often found as the sugar linking a glycan to asparagine in $\mathrm{N}$-linkages. The sugar binding proteins do contain potential sites for $\mathrm{N}$-glycan attachment, although the actual linkage of the glycan has yet to be reported. FlaI and FlaJ paralogs, BasE and BasF, appear to be involved in the biogenesis of the bindosome structure. Additionally, three small genes $b a s A, b a s B$, and $b a s C$ encoding proteins with type IV pilin-like signal peptides have also been identified. Deletion of these genes results in slow growth in media containing glucose and arabinose suggesting that these proteins have an accessory role in the assembly of the bindosome, perhaps sharing a function with the minor pilins in type IV pili assembly [78].

Very recently, a new cell surface appendage named the "Iho670 fiber" was detected on the surface of Ignicoccus hospitalis [24]. The Iho670 fibers are extremely brittle structures that are distinct from flagella and pili in the primary structure of the constituting protein and the fact that they are not motility organelles. Interestingly, the major component protein is synthesized with a type IV pilinlike signal peptide and processed by a prepilin peptidase 
homologue. While the isolated protein did not stain positively as a glycoprotein using the PAS stain, it has been previously observed that a negative PAS staining reaction also occurred with some archaeal flagellins that were later shown to be glycoproteins [9, 13, 79]. The fiber protein has potential N-linked sequons, and I. hospitalis does have an STT3 (oligosaccharyltransferase) homologue (Igni_0016; [4]). Since a type IV pilin-like system is also used for flagella, certain pili, and sugar binding proteins (the bindosome) in archaea, it may be a very widespread pathway used by archaea for assembling surface structures.

2.4. S Layers. S layers are a very common component of cell envelopes of prokaryotes in general but are especially prevalent on the cell surface of archaeal species [80, 81]. $S$ layers are monomolecular crystalline arrays of protein or glycoprotein subunits. While not appendages, they are, nonetheless, important extracellular components that are routinely composed, in archaea, of glycosylated proteins [5, $82,83]$. In many archaea, $S$ layers are the sole component of the cell envelope since archaea lack the typical bacterial wall component, murein. In these archaea, the S layer interacts directly with the underlying cytoplasmic membrane in an envelope structure unseen in bacteria [84]. Many archaeal $S$ layers have been shown to be composed of glycoproteins, with many having $\mathrm{N}$-linked glycans or a mixture of $\mathrm{N}$ - and O-linked glycans $[5,7,85]$. This is in contrast to bacterial S layer glycoproteins which have only O-linked glycans $[1,5]$. Many different functions have been postulated for S layers, including acting as a molecular sieve and, in archaea, as a shape maintaining structure $[84,86,87]$. In archaea, S layers often have long hydrophobic protrusions that integrate into the cytoplasmic membrane and result in a kind of periplasmic space between the canopy of the S layer and the underlying cytoplasmic membrane [88].

\section{Comparisons of $\mathbf{N}$-Glycosylation in the Three Domains}

Before delving into the specific N-linked glycans identified in Archaea and their assembly and role in archaeal surface structures, it is important to consider the similarities and variations in the $\mathrm{N}$-linked glycosylation systems in the three domains of life, Eucarya, Bacteria, and Archaea (Table 1).

The very first prokaryotic protein shown to be a glycoprotein was the S layer (cell surface glycoprotein, CSG) of Halobacterium salinarum [3], a historically important discovery that dispelled the longstanding belief that only eukaryotic cells had the capability to glycosylate proteins. Now, a well-defined model system for the bacterial process has been reported in Campylobacter jejuni [2, 89]. The fact that the Campylobacter $p g l$ system can be functionally transferred to E. coli has greatly aided its dissection [89]. Comparisons of the bacterial system to that of eukaryotic cells show obvious similarities as well as significant differences between these two domains with the Archaea adding even more variation.

Thus far, it seems that very few bacteria outside of the Campylobacterales appear to have an N-glycosylation system and only in Campylobacter species has the system been dissected. Among the bacteria, strong BLAST hits to the oligosaccharyltransferase PglB (complete with the conserved catalytic WWDXG motif) can be found in the genomes of Wolinella and Desulfovibrio [90] as well as Sulfurovum sp. NBC37-1, Nautilia profundicola, Sulfurospirillum deleyianum, Sulfurimonas denitrificans, Caminibacter mediatlanticus, Nitratiruptor sp. SB155-2, and Helicobacter pullorum, among others. It appears that the $\mathrm{N}$-linked glycosylation system is not as restricted as originally thought, and there appears to be little doubt that demonstration of $\mathrm{N}$-linked glycosylation systems in other bacteria will soon be reported. In contrast, the $\mathrm{N}$-glycosylation process appears to be almost universal in archaea where a readily identified oligosaccharyltransferase $(a g l B)$ required for the transfer of the completed glycan from a lipid carrier to the target protein [18] is found in almost all sequenced genomes [4, 91]. Interestingly, recent analysis of the comparative structure of oligosaccharyltransferases representing all three domains shows three types of catalytic centers. While a description of the differences in the three catalytic centers lies outside the boundaries of this paper, the interesting observation is that all eukaryotic oligosaccharyltransferases have a single type (E-type) and the bacterial PglB has a single different type (Btype) while different archaeal AglB divide into three groups (E, B, and A-type (archaeal type)), each with a different catalytic center and thus showing much more capacity for variability than the other two domains [91].

The N-glycosylation systems of Eucarya, Bacteria, and Archaea all are thematically similar, although all have distinctive traits (Table 1). In all organisms, the glycan is assembled sugar by sugar by specific glycosyltransferases using nucleotide activated sugars as substrates. The lipid carrier is undecaprenol diphosphate in Bacteria [92] while it is a dolichol derivative for both Eucarya and Archaea. In Eukarya, the carrier is dolichol pyrophosphate while in Archaea both the pyro and a monophosphate dolichol have been reported [93-95]. Early work in Halobacterium salinarum where there are, unusually, two different $\mathrm{N}$-linked glycans attached to the $S$ layer, indicated that the repeating unit glycan was assembled on a dolichol pyrophosphate carrier while the oligosaccharide glycan was assembled on a dolichol monophosphate carrier [96].

Assembly of the glycan occurs on the cytoplasmic face of the cytoplasmic membrane for Campylobacter, and the completed glycan is flipped by an ATP-dependent flippase, PglK [97], to the periplasmic side prior to its transfer to the target protein. In eukaryotic cells, the glycan is assembled on the cytosolic side of the ER membrane before being transferred to the lumen side where further additional sugars are added from dolichol-P sugars. The transfer to the lumen of the ER was assigned to the ATP-independent flippase Rft1 [98] although recent evidence casts doubt on that original assignment [99]. Recent work has indicated that the topology of the $\mathrm{N}$-glycosylation system in archaea is also with the assembly of the glycan on the cytoplasmic side of the cytoplasmic membrane [100] although the putative flippase remains unidentified. No $\mathrm{Rft} 1$ homologues appear in the genomes of $M$. maripaludis while BLAST searches using PglK 
TABle 1: Comparison of N-glycosylation in the three domains.

\begin{tabular}{|c|c|c|c|}
\hline Trait & Eukarya & Bacteria & Archaea \\
\hline Linking sugar & GlcNAc & Di-acetyl-bacillosamine & GlcNAc, GalNAc, Glucose \\
\hline Lipid carrier & Dolichol-PP & Undecaprenol-PP & Dolichol-PP, Dolichol-P \\
\hline Flippase & $\begin{array}{l}\text { Rft1; ATP-independent (Role of } \\
\text { Rft questioned) }\end{array}$ & PglK ATP-dependent & Unknown \\
\hline Sequon in target protein & $\mathrm{N}-\mathrm{X}-\mathrm{S} / \mathrm{T}(\mathrm{X} \operatorname{not} \mathrm{P})$ & D/E-Z-N-X-S/T (Z, X not P) & $\begin{array}{l}\mathrm{N}-\mathrm{X}-\mathrm{S} / \mathrm{T}(\mathrm{X} \operatorname{not} \mathrm{P}), \mathrm{N}-\mathrm{X}-\mathrm{N} / \mathrm{L} / \mathrm{V} \\
(\mathrm{X} \operatorname{not} \mathrm{P})\end{array}$ \\
\hline $\begin{array}{l}\text { Oligosaccharyl- } \\
\text { transferase }\end{array}$ & $\begin{array}{l}\text { STT3 subunit of multimeric } \\
\text { complex }\end{array}$ & $\begin{array}{l}\text { PglB single subunit (Stt3 } \\
\text { homologue) }\end{array}$ & $\begin{array}{l}\text { AglB single subunit (Stt3 } \\
\text { homologue) }\end{array}$ \\
\hline $\begin{array}{l}\text { Oligosaccharyl- } \\
\text { transferase catalytic type }\end{array}$ & E-type & B-type & A, B, and E-type \\
\hline $\begin{array}{l}\text { Site of assembly of } \\
\text { glycan }\end{array}$ & Cytosolic face of ER membrane & $\begin{array}{l}\text { Cytoplasmic face of cytoplasmic } \\
\text { membrane }\end{array}$ & $\begin{array}{l}\text { Cytoplasmic face of cytoplasmic } \\
\text { membrane }\end{array}$ \\
\hline Site of glycan transfer & Lumenal face of ER membrane & $\begin{array}{l}\text { External face of cytoplasmic } \\
\text { membrane }\end{array}$ & $\begin{array}{l}\text { External face of cytoplasmic } \\
\text { membrane }\end{array}$ \\
\hline
\end{tabular}

retrieve many strong hits due to the presence of many $\mathrm{ABC}$ transporters. Targeted deletions of likely candidates have so far failed to reveal the elusive flippase in archaea $[18,19]$.

The linking sugar connecting the glycan to the target Asn in the Asn-X-Thr/Ser motif is also different in the three domains. In the bacterial (Campylobacter) system, this is di-N-acetyl bacillosamine [101] (an early report of a Asn-rhamnose linkage for a glycan $\mathrm{N}$-linked to the $\mathrm{S}$ layer of Bacillus stearothermophilus [102] was later corrected [103]) while in eukaryotic cells this is typically $\mathrm{N}$-acetylglucosamine, although glucose is used in laminin [104]. In archaea, several different linking sugars have been reported in the limited structures so far determined, both $\mathrm{N}$-acetylglucosamine and $\mathrm{N}$-acetylgalactosamine as well as simple hexoses $[9,13,105,106]$. The transfer of the glycan to the target protein is carried out by an oligosaccharyltransferase. In Campylobacter, this is $\mathrm{PglB}$, and when the system is transferred to E. coli [89], PglB can transfer a variety of unnatural glycans to the $C$. jejuni acceptor protein AcrA but all the identified substrates contain either bacillosamine (the natural substrate), $\mathrm{N}$-acetylglucosamine, $\mathrm{N}$ acetylgalactosamine, or $\mathrm{N}$-acetylfucosamine at the reducing end, that is, they all contain an acetamido group at position 2 [107]. A similar conclusion was reached for the eukaryotic oligosaccharyltransferase [108], although this seems at odds with the $\beta$-glucosylasparagine linkage found in laminin [104]. This limitation may not exist for the archaeal AglB since there are instances in both $H$. salinarum and $H$. volcanii where the linking sugar is a hexose $[7,106]$.

The archaeal AglB seems quite adept at transferring incomplete glycans, as mutants in the various glycosyltransferases needed to assemble the complete glycan nevertheless have proteins possessing the truncated glycan variants. In the case of flagellins of methanococci, there appears to be almost quantitative transfer of truncated glycans by AglB, as nonglycosylated flagellins are not observed in any abundance in western blots of glycosylation mutants (Figure 1). There are reports of $\mathrm{PglB}$ having relaxed specificity: certainly a variety of unnatural glycans including LPS O-antigens

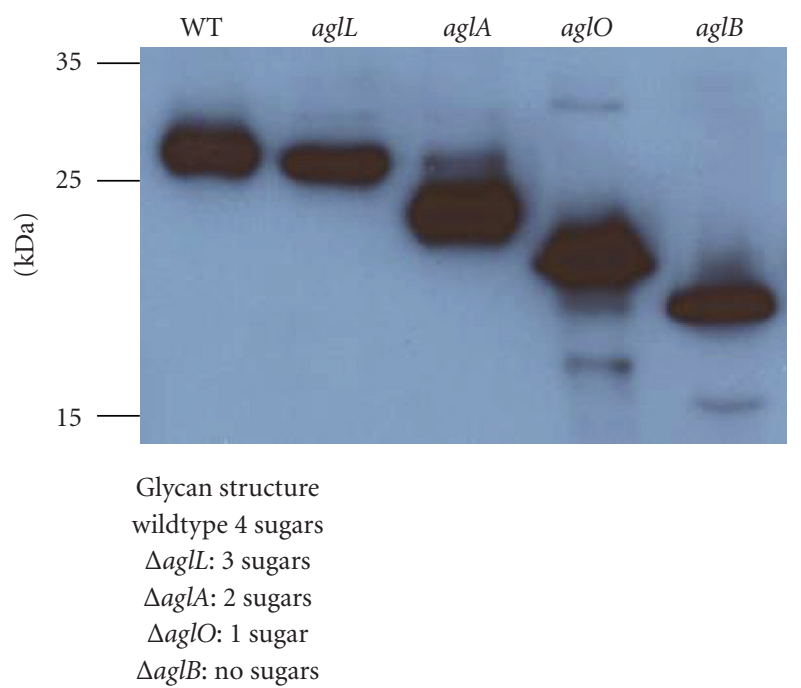

FIGURE 1: Immunoblot of wild-type M. maripaludis cells and mutants carrying deletions in various agl genes. Blots were developed with anti-flagellin antisera. Blot shows almost quantitative transfer of truncated glycans occurs.

can be added and also incomplete glycans transferred [92, 109]. However, other reports in the native Campylobacter host indicate that many truncated glycans are not well transferred to the target proteins [97]. This relaxed specificity is in contrast to the oligosaccharyltransferase complex in yeast, where truncated glycans and nonnative structures are generally not acceptable substrates for transfer [108, 110, 111]. All oligosaccharyltransferases (the STT3 subunit of the eukaryotic OT complex, PglB and AglB) contain the conserved motif (WWDYG). Mutations in this conserved motif result in loss of $\mathrm{N}$-linked glycosylation confirming its essential role in catalysis $[89,95]$.

The target for transfer of the assembled glycan is always an Asn residue in a conserved motif. This motif is N-X$\mathrm{S} / \mathrm{T}$ (X cannot be proline) in Eucarya but in Campylobacter 
this motif has an extended version, D/E-Z-N-X-S/T ( $\mathrm{Z}$ and $X$ cannot be proline) [112]. Examination of the sequences around the N-linked sequon in Archaea revealed that the bacterial extended motif is not found and indeed the simpler eukaryotic motif was used [113]. Interestingly, there is an unexplained variation found in the $\mathrm{S}$ layer of H. salinarum, where the position 2 Asn residue is occupied with a repeating unit $\mathrm{N}$-linked glycan. All other sites in the protein where $\mathrm{N}$ linked glycosylation occurs are occupied with an oligosaccharide glycan. Site-directed mutagenesis of that Asn-2 motif's serine (position 4) to valine, leucine, or asparagine did not prevent subsequent $\mathrm{N}$-glycosylation at that site [114]. No suitable explanation for this interesting finding has been presented. Initial suggestions that perhaps there were multiple oligosaccharyltransferases in $H$. salinarum were not substantiated by subsequent genome sequencing, where only a single oligosaccharyltransferase gene was found [4]. How the cell differentiates between sites that receive the oligosaccharide glycan or the repeating unit glycan is unknown.

The site of transfer of the glycan to the target proteins was shown to be external to the cell in Halobacterium [7]. Treatment of cells with bacitracin, which does not cross the cell membrane, inhibited the transfer of the repeating unit glycan but not the oligosaccharide glycan. Since bacitracin is known to inhibit glycosylation by binding to lipid pyrophosphates, this result suggested that assembly of the repeating unit glycan occurred using a lipid pyrophosphate carrier while the oligosaccharide glycan used a lipid monophosphate carrier. Transfer of glycan to a synthetic peptide that contained the N-linked target sequon, but was unable to cross the cytoplasmic membrane, was also shown. These data support the extracellular location of the AglB catalytic site.

Knockouts of the oligosaccharyltransferase gene aglB in M. maripaludis [18, 19], M. voltae [18], and $H$. volcanii [20] have demonstrated a marked reduction in target protein molecular weight consistent with a nonglycosylated target, as expected for cells lacking oligosaccharyltransferase activity. However, only with the oligosaccharyltransferase of Pyrococcus furiosus has an in vitro assay demonstrated that this subunit can catalyze the transfer of the glycan to the target sequon on peptides [17]. Work on the first crystal structure of any oligosaccharyltransferase revealed that the P. furiosus enzyme possessed a novel conserved motif (DK motif, Asp-X-X-Lys), which was subsequently confirmed in the yeast Stt3 subunit to be important for catalysis [17].

\section{Glycan Structures}

$\mathrm{N}$-linked glycan structures have been determined from a limited number of glycoproteins from a variety of archaea (Figure 2). However, only in the cases of M. voltae, $M$. maripaludis, and $H$. volcanii have genetic studies of the glycan assembly and biosynthesis accompanied the structural determination.

4.1. Methanococcus voltae. Mass spectrometry, in combination with NMR analysis, was utilized to reveal the structure of the glycan N-linked to flagellins and the $\mathrm{S}$ layer protein in M. voltae. All the potential N-linked sequons (Table 2) of the four flagellin structural proteins (FlaA, FlaB1, FlaB2, and FlaB3) were occupied (1 site was not identified in the coverage of the protein) [9]. The glycan structure was revealed to be a novel $\mathrm{N}$-linked trisaccharide of mass $779 \mathrm{Da}$ with the structure $\beta$-Man $p$ NAcA6Thr-(1-4)- $\beta$-GlcpNAc3NAcA(1-3)- $\beta$-GlcpNAc-Asn [9]. The glycan is attached to asparagine via $\mathrm{N}$-acetylglucosamine, with the second sugar being a diacetylated glucuronic acid and the terminal sugar being an unusually modified $\mathrm{N}$-acetylmannuronic acid substituted with a threonine residue at position 6. (Sugar abbreviations: GlcNAc, 2-acetamido-2-deoxyglucose; GlcNAc3NAcA, 2,3-diacetamido-2,3-dideoxyglucuronic acid; ManNAcA, 2-acetamido-2-deoxymannuronic acid.)

Recent studies have shown that other versions of $M$. voltae strain PS can also glycosylate both the flagellin and $S$ layer protein with a tetrasaccharide composed of the previously reported trisaccharide but with an additional residue of either 220 or $262 \mathrm{Da}$ mass [64].

4.2. Methanococcus maripaludis. The glycan attached to flagellins in M. maripaludis was determined by mass spectrometry and NMR techniques to be a tetrasaccharide of mass of $1036 \mathrm{Da}$, related to the structure previously determined for the $M$. voltae glycan but with significant differences [13]. The structure was demonstrated to be Sug-4- $\beta$-ManNAc3NAmA6Thr-4- $\beta$-GlcNAc3NAcA-3$\beta$-GalNAc-Asn (where Sug is a novel monosaccharide unit (5S)-2-acetamido-2,4-dideoxy-5-O-methyl- $\alpha$-l-erythrohexos-5-ulo-1,5-pyranose). An obvious difference in the two Methanococcus glycans is that M. maripaludis uses Nacetylgalactosamine (GalNAc) as the linking sugar while $M$. voltae employs $\mathrm{N}$-acetylglucosamine. In addition, the third sugar was identified as a variant of the terminal (third) sugar in the $M$. voltae glycan by the addition of a 3-acetamidino group. Finally, the terminal sugar in the $M$. maripaludis glycan was particularly labile and, in addition, is unique in being the first example of a naturally occurring diglycoside of an aldulose [13]. The N26 site of processed flagellins FlaB1 and FlaB2 (potential glycosylation site 38 in the unprocessed flagellins with attached signal peptide; Table 2) which represent the first potential $\mathrm{N}$-linked sequon in these M. maripaludis flagellins was not glycosylated [13]. This was unexpected since three of the $M$. voltae flagellins have an identically located $\mathrm{N}$-glycosylation site, and in all cases, these are occupied by glycan [9] (Table 2).

4.3. Haloferax volcanii. In Haloferax volcanii, seven potential $\mathrm{N}$-linked sequons are found within the S-layer glycoprotein (Table 2), and mass spectrometry provided insight into the composition of the glycan decorating at least two of these seven potential sites $[12,106]$. The glycan was identified as a pentasaccharide comprised of two hexoses, two hexuronic acids, and an additional $190 \mathrm{Da}$ saccharide attached via a hexose to Asn13 and Asn83 of the S layer protein [12]. The sequence of the pentasaccharide linked to Asn13 was 


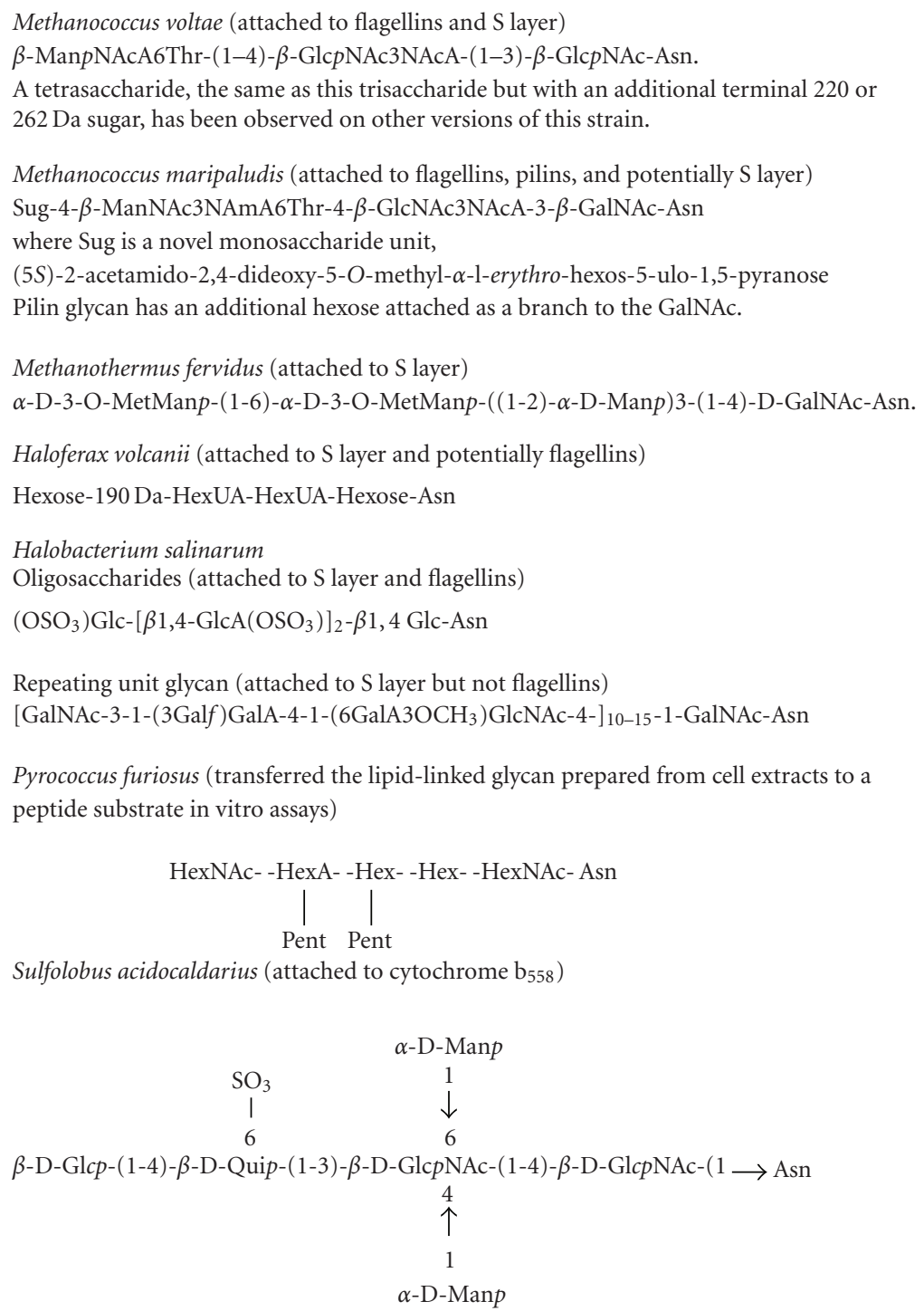

Figure 2: Structures of N-linked glycans in various Archaea.

determined to be hexose (Hex)-X-hexuronic acid (HexA)HexA-Hex-peptide (Figure 2), where $\mathrm{X}$ is a $190 \mathrm{Da}$ moiety recently revealed to be a methyl ester of hexuronic acid [115].

This structure is drastically different from the initial report of the N-linked glycan, attached at four of the potential seven sites, as a linear chain of $10 \beta$ 1,4-linked glucose residues with no amino sugars or uronic acids [11].

Analysis of the sequenced $H$. volcanii genome has also revealed the presence of two typical flagellin genes which have potential N-linked sites (Table 2).

4.4. Other Archaeal N-Linked Glycan Structures. The S layer protein of Halobacterium salinarum [3] is a truly remarkable protein with two different N-linked glycans (Figure 2), as well as a sulfated disaccharide of glucose and galactose attached in an O-linkage to threonine residues near the Cterminus of the molecule. One of the N-linked glycans is a repeating unit glycan attached via $\mathrm{N}$-acetylgalactosamine to the very $\mathrm{N}$-terminus of the protein at an asparagine at position 2. This pentasaccharide repeating unit (1020 repeats) contains unusual features including a methylated galacturonic acid and a furanosidic galactose linked peripherally to a linear chain of GalNAc-GalA-GalNAc [116]. The second $\mathrm{N}$-linked glycan, found in about 10 copies per protein, is a sulfated oligosaccharide linked to asparagine via glucose and this glycan is also found on the flagellins (Table 2). The glucose linking sugar is extended by $2-3 \beta-1,4$ linked glucuronic acids, which are sometimes replaced with iduronic acid.

An N-linked hexasaccharide glycan with the structure $\alpha$-D-3-O-MetMan $p$-(1-6)- $\alpha$-D-3-O-MetMan $p-((1-2)-$ $\alpha$-D-Manp)3-(1-4)-D-GalNAc-Asn (Figure 2) was reported on the $\mathrm{S}$ layer of the hyperthermophilic methanogen, Methanothermus fervidus [8]. As with the repeat unit glycan of $H$. salinarum and the glycan of $M$. maripaludis, the linking 
TABLE 2: Potential sites for N-glycosylation in selected archaeal proteins.

\begin{tabular}{|c|c|c|c|}
\hline Protein & $\begin{array}{l}\text { Length in amino acids } \\
\text { (including signal } \\
\text { peptide) }\end{array}$ & $\begin{array}{l}\text { Demonstrated } \\
\text { glycosylation }\end{array}$ & $\begin{array}{l}\text { Potential glycosylation sites } \\
\text { (amino acid position) }\end{array}$ \\
\hline \multicolumn{4}{|l|}{ M. voltae } \\
\hline FlaA & 219 & Yes & 38,175 \\
\hline FlaB1 & 218 & Yes & $38,71,77,115,136$ \\
\hline FlaB2 & 216 & Yes & $38,72,77,113,172,208$ \\
\hline FlaB3 & 239 & Yes & 115,128 \\
\hline S layer & 581 & Yes & 107,137 \\
\hline \multicolumn{4}{|l|}{ M. maripaludis } \\
\hline FlaB1 & 211 & Yes & $38,12,128,168$ \\
\hline FlaB2 & 216 & Yes & $38,78,122,131,136$ \\
\hline FlaB3 & 210 & Yes & 150,175 \\
\hline MMP1685 Pilin & 74 & Yes & $39,49,52,71$ \\
\hline MMP0233 Pilin & 129 & No & $63,87,94,108$ \\
\hline MMP0236 Pilin & 132 & No & $34,74,83,94,98,119,126$ \\
\hline MMP0237 Pilin & 151 & No & $72,82,89,95$ \\
\hline S layer & 575 & No & 535 \\
\hline \multicolumn{4}{|l|}{ H. volcanii } \\
\hline FlaA1 & 213 & No & $70,115,128,134,162,172$ \\
\hline FlaA & 220 & No & $78,95,112,124$ \\
\hline S layer & 827 & Yes & $\begin{array}{l}47,114,308,313,404,532 \text {, } \\
766\end{array}$ \\
\hline \multicolumn{4}{|l|}{ H. salinarium } \\
\hline FlgA1 & 196 & Yes & $84,97,125$ \\
\hline FlgA2 & 194 & Yes & $80,93,126$ \\
\hline FlgB1 & 193 & Yes & $80,93,123$ \\
\hline FlgB2 & 196 & Yes & $84,97,125$ \\
\hline FlgB3 & 193 & Yes & $80,93,123$ \\
\hline S layer & 852 & Yes & $\begin{array}{l}36,51,327,339,398,438 \\
513,643,727,751,787 \\
811,815\end{array}$ \\
\hline
\end{tabular}

sugar is $\mathrm{N}$-acetylgalactosamine. The protein itself has 20 potential N-linked sequon sites with half of them occupied with the glycan.

Cytochrome $b_{558-566}$ in Sulfolobus acidocaldarius [15] is a highly glycosylated membrane protein modified at least 7 positions with a hexasaccharide. The glycan consists of 2 residues each of mannose and $\mathrm{N}$-acetylglucosamine and one each of glucose and the rare sugar, 6-deoxy6-sulfoglucose (6-sulfoquinovose) (Figure 2). The linkage is through $\mathrm{N}$-acetylglucosamine. A cytoplasmic membrane protein in Thermoplasma acidophilum that contains a highly branched glycan, composed mainly of mannose, N-linked through an $\mathrm{N}$-acetylglucosamine has also been reported [16]. In addition, it was shown in Pyrococcus furiosus that the purified oligosaccharyltransferase could transfer a lipidlinked heptasaccharide prepared from $P$. furiosus cells to an Asn within a sequon Asn-X-Thr/Ser contained in a peptide substrate [17]. The heptasaccharide is branched and consisted of two N-acetylhexosamines, two hexoses, a hexA, and two pentoses.
The cell sheath of Methanosaeta concilii, the outermost layer of the complex cell envelope of this organism, was reported to be a glycoprotein with the glycan N-linked via a rhamnose residue [117]. However, the rhamnosyl peptide identified was reported as Rha-Asn-Glu-Gly-Ser and not the canonical Asn-X-Ser/Thr sequon.

\section{Assembly of the Glycans}

5.1. Methanococcus voltae. Most of the enzymes needed to assemble the glycan $\mathrm{N}$-linked to flagellins and S-layer have been identified in both M. voltae and M. maripaludis. The glycan of $M$. voltae cultured long term in the Jarrell lab has a three sugar component [9], although a fourth sugar has been detected in other versions of this strain [64]. Likely the Jarrell version of the strain developed a spontaneous mutation affecting the biosynthesis or addition of the fourth sugar. Utilizing a very primitive genetic system that allowed only insertional inactivation of targeted genes, Chaban et al., in a series of papers, identified the glycosyltransferases and the 
oligosaccharyltransferase needed for its assembly. The initial study inactivated a gene designated aglA which resulted in faster migrating flagellins and $\mathrm{S}$ layer proteins than observed in the wild type [18]. When flagella from the aglA mutant were isolated and subjected to mass spectroscopy analysis, it was determined that the terminal sugar, the modified mannuronic acid, was missing, indicating a role for AglA in the transfer of this last sugar onto the glycan. The linking sugar for the $M$. voltae glycan is $\mathrm{N}$-acetylglucosamine, and a gene thought to catalyze the addition of this first sugar onto the dolichol lipid carrier was identified in the M. voltae genome. Repeated attempts to inactivate this gene failed, indicating perhaps its essential nature in M. voltae. This gene, designated $a g l H$, was the only one in the M. voltae genome that belonged to Pfam family PF00953 (glycosyltransferase family 4), the family that includes the eukaryotic gene alg7, encoding the enzyme $\mathrm{N}$-acetylglucosamine-1phosphate transferase that attaches $\mathrm{N}$-acetylglucosamine to the eukaryotic dolichol lipid carrier, in the first dedicated step of the $\mathrm{N}$-glycosylation process. Evidence that the $M$. voltae gene did, in fact, encode the first glycosyltransferase for assembly of the archaeal glycan was obtained when it was shown that $a g l H$ could complement a conditionally lethal mutation in alg7 in Saccharomyces cerevisiae [118]. With AglA attaching the last of the three sugars and $\mathrm{AglH}$ attaching the first, this left identification of the glycosyltransferase for the second sugar. Unexpectedly, two genes annotated as glycosyltransferases were shown to be involved in this step of glycan assembly [64]. Inactivation of either aglC or its adjacent gene alg $K$ resulted in flagellins that had molecular masses smaller than those of aglA mutants missing the third sugar but higher than flagellins from that of an oligosaccharyltransferase mutant that would be completely nonglycosylated. Both AglC and AglK are involved in either transfer or biosynthesis of the second sugar of the glycan.

A key enzyme in the $\mathrm{N}$-glycosylation process is the oligosaccharyltransferase which transfers the assembled glycan to the target protein. This enzyme has a highly conserved catalytic motif (WWDXG) which simplifies its identification. In $M$. voltae, this gene, designated $a g l B$, was disrupted, and the mutants carrying this disruption has $\mathrm{S}$ layer protein and flagellin molecular masses smaller than those found in any of the other $a g l$ mutants, consistent with this enzyme being responsible for the transfer of the N-glycan [18].

Since the oligosaccharyltransferase gene could be inactivated, N-linked glycosylation appears to be a nonessential pathway in $M$. voltae. This means that the inability to inactivate the first glycosyltransferase is unrelated to its role in N-linked glycosylation and must lie in its role in another pathway essential for the cell, unless inactivation of this gene at this site of the chromosome is simply highly unfavoured. One such essential pathway may be in the biosynthesis of the methanogenesis cofactor, component B (7-mercaptoheptanoylthreonine) [119] which has been reported to contain an acetamido sugar disaccharide consisting partly of $\mathrm{N}$-acetylglucosamine [120]. This cofactor is essential for the terminal step in methanogenesis catalyzed by methyl CoM reductase [120], and its defective biosynthesis would be lethal. Interestingly, it was not possible to delete the corresponding gene in M. maripaludis either [19], even though the linking sugar in M. maripaludis is not $\mathrm{N}$-acetylglucosamine but $\mathrm{N}$-acetylgalactosamine [13]. This further suggests that the essential role that enzyme plays lies outside the $\mathrm{N}$-linked glycosylation system.

No flippase, proposed to be necessary to flip the assembled lipid-linked glycan to the external face of the cytoplasmic membrane before its attachment to the target protein by the oligosaccharyltransferase, was identified in the M. voltae system. Candidate genes were either inactivated without the predicted phenotype or were unable to be inactivated $[18,19]$.

A summary of the site of action of the M. voltae glycosyltransferases and oligosaccharyltransferase is shown in Figure 3.

5.2. M. maripaludis. In 2005, a genetic system was reported for an M. voltae relative, that is, M. maripaludis. This system allowed for a markerless inframe deletion of targeted genes and their subsequent complementation by plasmid borne versions [121]. As a result, this organism became a natural choice for continued investigations on the $\mathrm{N}$ linked glycosylation system in archaea. Structural work on the glycan of $M$. maripaludis flagellins revealed interesting differences, including its tetrasaccharide nature, its unique terminal sugar, and the fact that, unlike the $M$. voltae glycan, its attachment to the protein was via $\mathrm{N}$-acetylgalactosamine [13]. Attempts to identify the likely 4 glycosyltransferases involved in its assembly began with targeting the approximately dozen annotated glycosyltransferase genes in the published genome. One locus was found to harbour three glycosyltransferases involved in assembly of the N-linked glycan of M. maripaludis. These genes, MMP1079, MMP1080 and MMP1088 designated $a g l O$, aglA, and $a g l L$, respectively, were separated by other genes, some of which were later shown to be involved in the biosynthesis of the component sugars (see below). Located elsewhere on the genome was the oligosaccharide transferase, aglB (MMP1424). Deletions of each of these genes lead to decreases in the molecular mass of the flagellins compared to wild-type cells, with the aglB mutant, presumably completely lacking the N-linked glycan, possessing flagellins with the lowest mass [19]. In order, the flagellin masses decreased in size from wild-type to the $a g l L$, $a g l A$, algO, and $a g l B$ mutants. Mass spectrometry analysis of purified flagellins from the aglL mutant indicated it lacked the terminal sugar as well as the threonine attached to the third sugar. Similar analysis of flagella from the aglA mutant showed only the first two sugars present on the glycan. MMP1080 was designated aglA since it is $55 \%$ similar to the M. voltae aglA sequence [18], and the two enzymes transfer a very similar modified mannuronic acid residue to an identical diacetylated glucuronic acid (second sugar). All of the deleted genes could be complemented with plasmid borne copies resulting in wild-type glycan formation. The MS data on the structure of the aglL mutant glycan is unusual in that two significant changes were noted. The fourth sugar was entirely missing but also the threonine attachment to the third sugar was missing. In theory, AglL could be responsible for either of these two changes (or both). Because of the 
$\mathrm{N}$-linked glycan in Haloferax volcanii

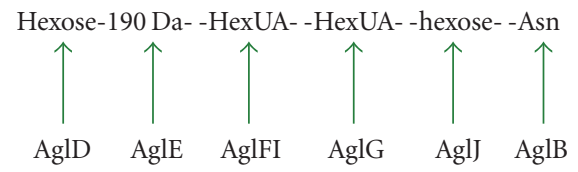

(a)

$\mathrm{N}$-linked glycan in Methanococcus maripaludis

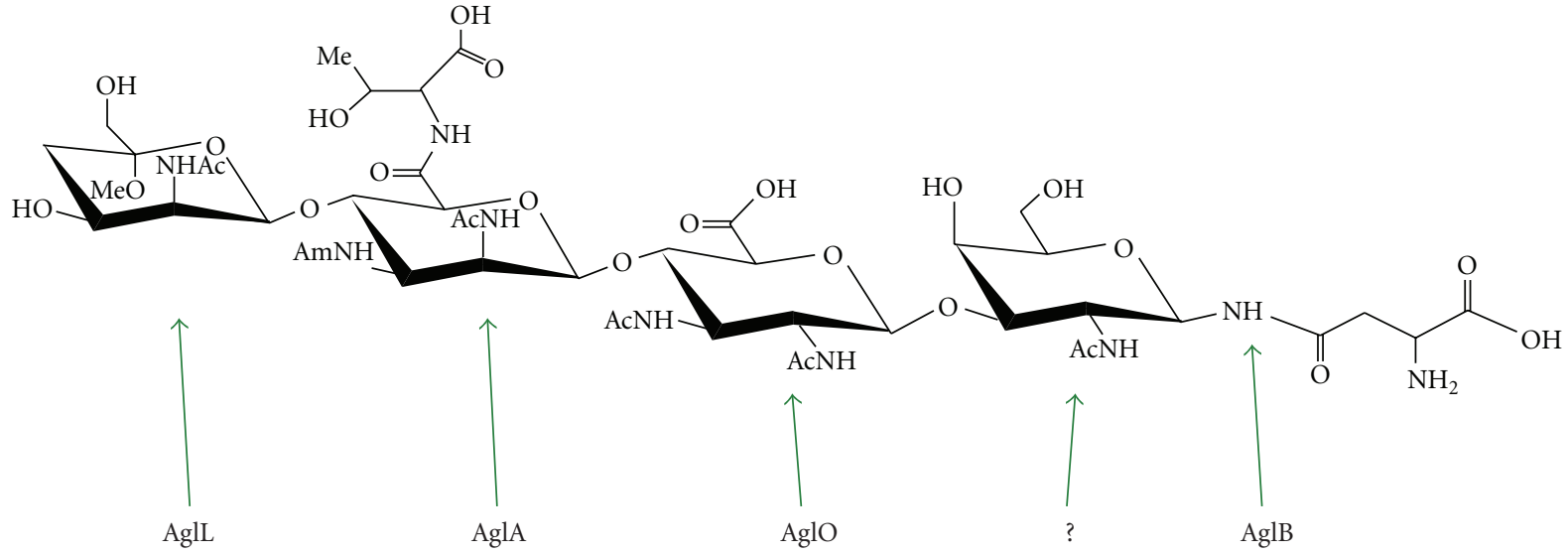

(b)

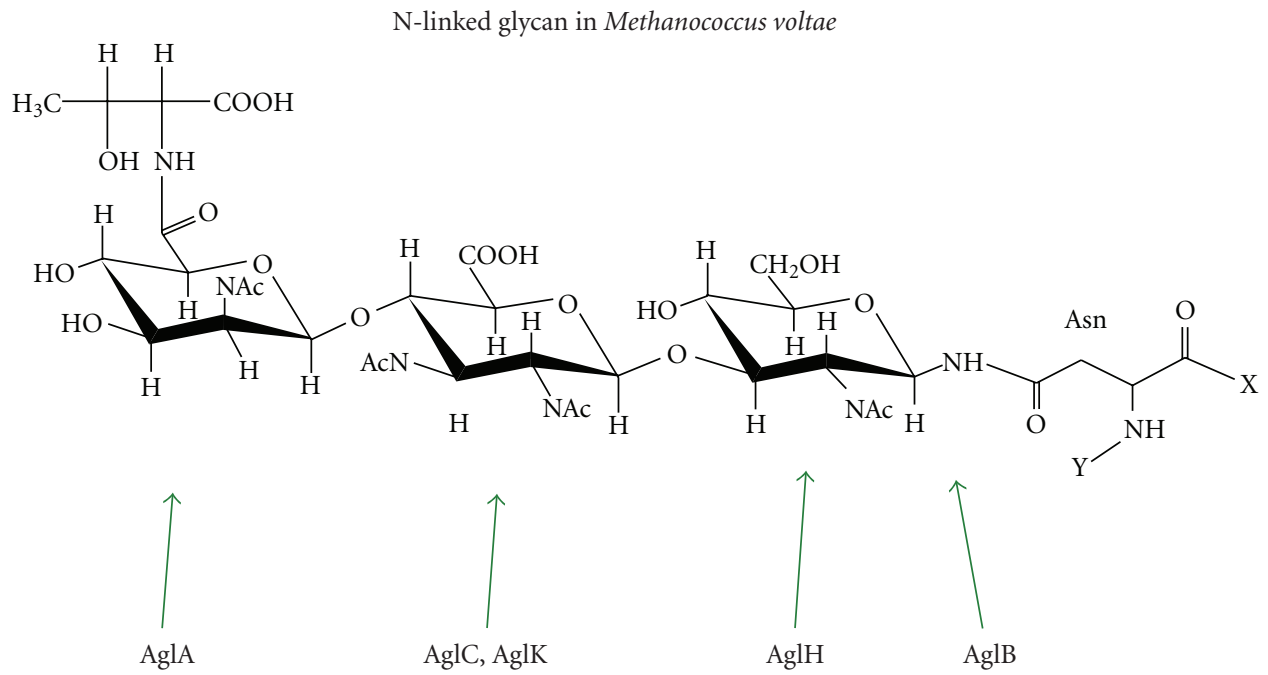

(c)

FIGURE 3: Stage of action of various glycosyltransferases and oligosaccharyltransferase in the N-linked glycan assembly of Haloferax volcanii, Methanococcus maripaludis, and Methanococcus voltae.

strong similarity of AglL to known glycosyltransferases, we believe that it is transferring the final sugar and not the threonine. This would suggest that the threonine attachment likely occurs to the third sugar only after the four-sugar glycan has been completed. Without the attachment of the fourth sugar in the aglL mutant, the threonine cannot be attached to the third sugar. The enzyme responsible for the threonine attachment has not been identified.
These studies identified the oligosaccharyltransferase and three of the four needed glycosyltransferases. Still unaccounted for is the glycosyltransferase responsible for attaching the first sugar to the dolichol lipid carrier. In $M$. voltae, this was identified as a eukaryotic alg7 homologue. However, in M. maripaludis the linking sugar is not $\mathrm{N}$ acetylglucosamine but rather $\mathrm{N}$-acetylgalactosamine. The glycosyltransferase transferring an $\mathrm{N}$-acetylgalactosamine 
to the dolichol lipid to start assembly of the glycan has not been identified. Recently, an epimerase that converts $\mathrm{N}$-acetylglucosamine-P-P-undecaprenol to $\mathrm{N}$ acetylgalactosamine-P-P-undecaprenol in O-antigen biosynthesis in E. coli was reported [122]. While such an activity has not been reported for converting $\mathrm{N}$-acetylglucosamine-P-Pdolichol to $\mathrm{N}$-acetylgalactosamine P-P-dolichol in eukaryotes, the possibility exists that $\mathrm{AglH}$ assembles an $\mathrm{N}$ acetylglucosamine-dolichol precursor that is subject to epimerization to create the final $\mathrm{N}$-acetylgalactosamine version. A BLAST search using the E. coli epimerase did identify a strong hit in M. maripaludis, MMP1090, which when deleted resulted in a large downshift in flagellin molecular weight, suggesting a flagellin with a much reduced glycan chain (unpublished data). All of the other annotated glycosyltransferase genes of $M$. maripaludis have been targeted for deletion in efforts to identify this first glycosyltransferase. However, all potential candidates successfully deleted did not yield the expected phenotype (flagellin molecular weight identical to that of $a g l B$ mutants). Several candidate genes were not successfully deleted, however, and additional glycosyltransferase candidates have been identified manually in the complete sequence (unpublished data). M. voltae, $M$. maripaludis and $H$. volcanii encode many more glycosyltransferases than are needed solely for $\mathrm{N}$-linked glycan assembly. These are presumably involved in other processes, such as O-linked glycosylation and perhaps glycolipid and cofactor synthesis since, at least in methanogens, sugars can be shared among those processes [120,123].

As with $M$. voltae, attempts to identify the putative flippase in M. maripaludis have been unsuccessful, either due to an inability to delete targeted candidates or because targeted candidate genes for the flippase that were deleted did not have the expected phenotype.

A summary of the site of action of the $M$. maripaludis glycosyltransferases and oligosaccharyltransferase is shown in Figure 3.

5.3. Haloferax volcanii. The Eichler lab has presented a series of papers that identify a role for many agl genes in the biosynthesis, assembly, and transfer of a pentasaccharide glycan N-linked to the S layer protein at positions Asn 13 and Asn 83 [12]. The study of the glycosylation of this target is complicated by the presence of O-linked glycans as well. The glycan attached to $S$ layer in $H$. volcanii consists of a hexose, followed by 2 hexuronic acids, a $190 \mathrm{Da}$ sugar (a methyl ester of a hexuronic acid), and finally another hexose with the link to the Asn being via a hexose [12], an unusual N-linkage first reported in Halobacterium salinarum [93].

Unlike in Methanococcus species where the aglB oligosaccharyltransferase is located at a distance from many of the glycosyltransferases needed to assemble the glycan, in $H$. volcanii one large $a g l$ cluster spanning nearly $20 \mathrm{~kb}$ includes all but one of the genes ( $\operatorname{aglD}$ ) identified as being involved in the $\mathrm{N}$-glycosylation process $[124,125]$. A number of gene products have been assigned glycosyltransferase function: AglG for addition of the hexuronic acid at position 2, AglI for addition of the hexuronic acid at position 3 [126], AglE for the addition of the $190 \mathrm{Da}$ sugar [127], and AglD for the addition of the terminal hexose [12]. In addition, there is evidence for AglJ being the glycosyltransferase responsible for transfer of the first sugar.

The topology of certain enzymes, namely, AglJ and AglD, involved in early and late stages of the $\mathrm{N}$-glycosylation process was demonstrated to be with their $\mathrm{N}$-terminal domains (likely containing their catalytic sites) facing the cytoplasm, indicating that assembly of the glycan on the dolichol lipid carrier occurs on the cytoplasmic face of the cytoplasmic membrane before flipping to the external face for transfer onto the target proteins via AglB [100].

A summary of the site of action of the $H$. volcanii glycosyltransferases and oligosaccharyltransferase is shown in Figure 3.

Genetic analysis of the N-linked system in other archaeal species has not yet been reported, even for those in which $\mathrm{N}$ linked glycan structures have been determined. This is due, to some cases, to the complete lack of a suitable genetic system.

\section{Biosynthesis Genes}

Although a biosynthetic pathway for sugar residues involved in the glycan structure displayed in bacteria is well characterized [2], it is only very recently that the enzymes responsible for the process in Archaea have been discovered. Currently, the majority of data regarding the glycan biosynthesis pathway is focused around two archaeal species, M. maripaludis and $H$. volcanii.

6.1. M. maripaludis. Recent in vitro experimentation, using heterologously expressed and purified proteins predicted to be involved in glycosylation, helped to describe the biosynthesis of the acetamido sugar subunit precursors in M. maripaludis [119]. MMP1680 was shown to transamidate and epimerize the reaction of fructose-6-phosphate and L-glutamine to glucosamine-6-phosphate and glutamate, respectively. Additionally, the conversion of glucosamine-6phosphate to glucosamine-1-phosphate through the activity of MMP1077 was demonstrated. The immediate neighbor of MMP1077, MMP1076 (GlcN-1P uridyltransferase/acetylase) acts in a bifunctional manner, both acetylating the 2amino group and facilitating the transfer to UTP producing UDP- $N$-acetylglucosamine. This sugar subunit is the immediate precursor for several different biosynthetic pathways resulting in the sugar residues that are added to the glycan structure. Interestingly, $\mathrm{N}$-acetylglucosamine is the linking residue of the $\mathrm{N}$-glycan in M. voltae [9] while $\mathrm{N}$-acetylgalactosamine, which could be derived from $\mathrm{N}$-acetylglucosamine through the activity of an epimerase, fulfills this role in M. maripaludis [13], thus emphasizing the importance of the description of this pathway to understanding glycosylation in Archaea. MMP0705 (WecB) catalyses the isomerization of UDP- $N$-acetylglucosamine to UDP-N-acetylmannosamine [119], and MMP0706, the UDP-ManNAc 6-dehydrogenase (WecC), oxidizes UDP- Nacetylmannosamine to UDP- N-acetylmannosaminuronate, a direct precursor to the third sugar of the M. maripaludis glycan. Additionally, component B has been reported to 
have an attached N-acetylmannosaminuronate $\beta 1-4$ UDP$N$-acetylglucosamine disaccharide, and, since component $\mathrm{B}$ is essential for methanogenesis, disruption of its sugar moiety may lead to an inactive form and cell death. Attempts to delete either MMP0705 or MMP0706 have so far been unsuccessful (unpublished data), indicating a possible essential role of these enzymes in the cell, likely in component B biosynthesis. 2-acetamido sugars such as those discussed have also been found in M. voltae glycolipids [123], while glycolipid structures in $M$. maripaludis have not been reported.

In addition to this in vitro work, techniques utilizing inframe deletions of putative glycosylation genes have proven to be particularly useful. The first major finding reported in the biosynthetic pathway using this technique was the gene MMP0350. The gene, which shows strong sequence similarity to known acetyltransferases, appears to attach an acetyl group to the second sugar of the glycan, a diacetylated glucuronic acid. Lack of this modification resulted in an inability of the cells to attach the second sugar and left a truncated glycan of only 1 sugar [128].

An inframe deletion of MMP1081 resulted in a truncated glycan which was shown by mass spectrometry to be missing the acetamidino group of the third sugar as well as the entire fourth sugar (unpublished results). The homology to WpbG suggested MMP1081 as an acetamidino-transferase responsible for addition of this modification to the third sugar (unpublished results). The glycan of $M$. voltae strain PS has this sugar without the acetamidino group added. Unexpectedly, a strong homologue of MMP1081 is found in the genome of $M$. voltae A3. If this gene is also present and expressed in M. voltae strain PS, the strain in which the glycan structures have been determined, why the acetamidino group would not be added to the third sugar is unknown.

A second gene in this region has been experimentally confirmed to have a role in the glycosylation pathway. MMP1085, annotated as a methyl transferase, was shown to be responsible for the addition of a methyl group to the terminal sugar. Mutants in this gene were first detected to have a small downward shift in flagellin molecular weight in western blots, and subsequent mass spectrometry analysis of purified flagella from the MMP1085 mutant determined the lack of the methyl group (unpublished results). Several other genes in this locus are cotranscribed with either MMP1081 or MMP1085, and deletions in MMP1083 but not MMP1082 or MMP1087 appear to result in smaller flagellins in western blots suggesting that they also have defects in their glycan although this needs confirmation by mass spectrometry (unpublished data).

A summary of the deletion mutants studied in $M$. maripaludis so far and their effects on glycan structure and the flagella system are summarized in Table 3.

6.2. H. volcanii. Several genes have been identified in the glycan biosynthesis pathway of the pentasaccharide expressed on the $H$. volcanii surface layer, through deletion analysis as well as in vitro biochemical characterization $[115,125]$. The coordinated actions of AglM and AglF have been demonstrated. AglM functions as a UDP-glucose dehydrogenase, which catalyzes the generation of UDP-glucuronic acid from UDP-glucose, and is involved in the biosynthesis of the hexuronic acid at position 2 and likely also the one at position 3. AglF, a glucose-1-phosphate uridyltransferase, acts in conjunction with AglM in the biosynthesis of the hexuronic acid at position 3 but not, however, the one found at position 2 [125].

In addition, several other genes have been assigned roles in the $\mathrm{N}$-linked glycosylation process, specifically aglP, $a g l Q$, and $a g l R$, based partly on their cotranscription with known agl genes [124]. Recently, Magidovich et al. [115] have confirmed the action of AlgP as an S-adenosyl-Lmethionine-dependent methyltransferase as had been previously predicted through bioinformatics analysis [124]. This enzyme is responsible for the addition of a methyl group to the hexuronic acid found at position four of the $H$. volcanii glycan structure. A tagged version of AglP located to the cytoplasm and biochemical assays confirmed its ability to transfer methyl groups to membrane fragments of $H$. volcanii wild-type cells but not to those of an aglE mutant which lacks the 4 th sugar. Interestingly, aglP mutants had only a tetrasaccharide attached to their S layer; apparently the methyl group addition to sugar 4 is required for subsequent attachment of the terminal sugar. Protein sequence comparisons between AlgP of $H$. volcanii and the previously discussed $M$. maripaludis methyltransferase MMP1085 suggest low sequence identity, likely due to structural differences of the modified sugar in each glycan.

These in vitro studies, along with those on the P. furiosus AglB [17, 129], represent significant steps forward in the analysis of the archaeal $\mathrm{N}$-glycosylation mechanism.

A summary of the deletion mutants studied in $H$. volcanii so far and their effects on glycan structure, S layer, and cell growth are summarized in Table 4.

\section{Effects of Glycan Modifications on Surface Structures}

7.1. Flagella. Archaeal flagellin subunits have proven to be a rich resource as reporter proteins in the study of $\mathrm{N}$-linked glycosylation in Archaea. Effects of deletions of genes involved in the N-glycosylation pathway of both $M$. voltae and $M$. maripaludis can typically be visualized by faster migration of flagellin subunits through SDS-PAGE and western blot analysis, due to a decrease in the molecular weight corresponding to the truncated glycan $[18,19]$. Due to the relatively small size of flagellin subunits and the multiple sites of attachment of glycan, even very minor changes in the structure of the glycan have been resolved.

It has been previously demonstrated that the flagella structure is dependent on having at least a two-sugar glycan attached to flagellin subunits in both $M$. voltae and M. maripaludis $[18,19]$. Thus, mutants in aglA, the glycosyltransferase adding the third (terminal) sugar in the $M$. voltae glycan, are still flagellated while deletions in $\operatorname{algC}$ or $a g l K$ which are needed to add the second sugar, as well as in the oligosaccharide transferase, aglB, 
TABLE 3: Effects of agl gene deletions on flagellin glycosylation in M. maripaludis.

\begin{tabular}{|c|c|c|c|c|c|}
\hline Gene deletion & Function & Glycan structure & MW shift of flagellin & Flagella & Effect on motility \\
\hline $\operatorname{aglL}$ & 4th GTase & $\begin{array}{l}\text { Missing 4th sugar and } \\
\text { Thr on 3rd sugar }\end{array}$ & Yes & Yes & $\begin{array}{l}\text { Decreased compared } \\
\text { to WT }\end{array}$ \\
\hline $\operatorname{aglA}$ & 3rd GTase & $\begin{array}{l}\text { Missing 3rd and 4th } \\
\text { sugars }\end{array}$ & Yes & Yes & $\begin{array}{l}\text { Decreased compared } \\
\text { to aglL mutant }\end{array}$ \\
\hline aglO & 2nd GTase & $\begin{array}{l}\text { Missing 2nd, 3rd, and } \\
\text { 4th sugars }\end{array}$ & Yes & No & Nonmotile \\
\hline $\operatorname{aglB}$ & OTase & No glycan & Yes & No & Nonmotile \\
\hline MMP0350 & $\begin{array}{l}\text { Acetyl } \\
\text { transferase }\end{array}$ & $\begin{array}{l}\text { Missing } 2 \mathrm{nd}, 3 \mathrm{rd} \text {, and } \\
4 \text { th sugars }\end{array}$ & Yes & No & Nonmotile \\
\hline MMP1081 & $\begin{array}{l}\text { Acetamidino } \\
\text { transfer }\end{array}$ & $\begin{array}{l}\text { Missing } 4 \text { th sugar and } \\
\text { acetamidino group of } \\
\text { 3rd sugar }\end{array}$ & Yes & Yes & $\begin{array}{l}\text { Decreased compared } \\
\text { to WT }\end{array}$ \\
\hline MMP1085 & $\begin{array}{l}\text { Methyl } \\
\text { transferase }\end{array}$ & $\begin{array}{l}\text { Missing methyl group } \\
\text { of } 4 \text { th sugar }\end{array}$ & Yes & Yes & To be determined \\
\hline
\end{tabular}

TABLE 4: Effects of agl gene deletions on S layer glycosylation in $H$. volcanii.

\begin{tabular}{|c|c|c|c|c|c|c|c|}
\hline Gene deletion & Function & Glycan structure & $\begin{array}{l}\text { Growth in high } \\
\text { salt }\end{array}$ & $\begin{array}{l}\text { MW shift of S } \\
\text { layer }\end{array}$ & $\begin{array}{l}\text { Susceptibility of } \\
\text { S layer to } \\
\text { proteases }\end{array}$ & $\begin{array}{l}\text { Shedding of S } \\
\text { layer }\end{array}$ & $\begin{array}{l}\text { S layer } \\
\text { symmetry }\end{array}$ \\
\hline$a g l B$ & OTase & No glycan & Deficient & Yes & Same as WT & Increased & No effect \\
\hline$a g l D$ & 5th GTase & $\begin{array}{l}\text { Missing 5th } \\
\text { sugar }\end{array}$ & Deficient & Yes & Less than WT & Decreased & $\begin{array}{l}\text { Symmetry } \\
\text { defect }\end{array}$ \\
\hline $\operatorname{aglE}$ & 4th GTase & $\begin{array}{l}\text { Missing 4th and } \\
\text { 5th sugars }\end{array}$ & No effect & No & Same as WT & Same as WT & No effect \\
\hline $\operatorname{aglF}$ & $\begin{array}{l}\text { Glucose-1-P } \\
\text { Uridyltrans- } \\
\text { ferase (sugar } \\
\text { 3) }\end{array}$ & $\begin{array}{l}\text { Mix of mono } \\
\text { and } \\
\text { disaccharides }\end{array}$ & No effect & Yes & More than WT & Same as WT & No effect \\
\hline$a g l G$ & 2nd GTase & $\begin{array}{l}\text { Missing last } 4 \\
\text { sugars }\end{array}$ & No effect & Yes & More than WT & Same as WT & No effect \\
\hline agli & 3rd GTase & $\begin{array}{l}\text { Mix of mono } \\
\text { and } \\
\text { disaccharides }\end{array}$ & No effect & Yes & More than WT & Same as WT & No effect \\
\hline $\operatorname{aglM}$ & $\begin{array}{l}\text { UDP-Glucose } \\
\text { dehydrogenase } \\
\text { (sugars } 2 \text { and } 3 \text { ) }\end{array}$ & $\begin{array}{l}\text { Missing last } 4 \\
\text { sugars }\end{array}$ & Not reported & Yes & More than WT & Not reported & Not reported \\
\hline $\operatorname{aglP}$ & $\begin{array}{l}\text { Methyl } \\
\text { transferase } \\
\text { (sugar 4) }\end{array}$ & $\begin{array}{l}\text { Missing 5th } \\
\text { sugar and } \\
\text { methyl group of } \\
\text { sugar } 4\end{array}$ & Not reported & Not reported & More than WT & Not reported & Not reported \\
\hline
\end{tabular}

are completely nonflagellated $[18,64]$. Similarly, for $M$. maripaludis, mutants that result in the loss of the terminal sugar $(a g l L)$ or the third sugar $(\operatorname{aglA})$ are still flagellated while a mutant in $a g l O$, responsible for transferring the second sugar or in $a g l B$, is nonflagellated [19]. An acetyltransferase gene, MMP0350, likely responsible for addition of an acetyl group to the second sugar (the diacetylated glucuronic acid) $[19,128]$, results in flagellin with apparently a single sugar added, judged solely by apparent molecular weight comparisons to the corresponding molecular weights of various glycosyltransferase mutants. In accordance with the 2-sugar glycan rule, these mutants were also nonflagellated.
Additionally, one major advantage of examining glycan modification on the flagella is the ability to perform motility assays, thus demonstrating the in vivo importance of glycan for the proper functioning of this particular surface structure. For cells that assemble flagella, this technique yields measurable differences in the swimming capabilities of strains harbouring disruptions in the glycosylation pathway when compared to wild-type cells. It has been previously reported that cell motility decreases in accordance with the degree of truncation from the wild-type glycan. $M$. maripaludis cells lacking the terminal sugar due to the deletion of aglL swim less distance than wild type in motility 
agar $(0.25 \%$ agar), but a greater distance than cells which are lacking the third sugar due to inactivation of aglA [19]. In agreement with this, a mutant in MMP1081, demonstrated to be responsible for addition of an acetamidino group to the third sugar, swims a distance intermediate to that of the aglA and aglL mutants (unpublished results).

Undermodified flagellins of $H$. salinarum were also found to result in aberrant effects on flagella stability. In this instance, a mutant that overproduced flagella and released them into the media was found to be producing flagellins of lower molecular weight compared to wild-type cells suggestive of an underglycosylation. The exact difference in glycan structure was not reported [14]. In addition, when bacitracin, a known inhibitor of glycosylation, was added to growth medium of Methanococcus deltae, the cells became nonflagellated with flagellin molecular weight shifted to a lower molecular weight, again suggestive of underglycosylation. No structures for the flagellin glycans of the wild-type or bacitracin-treated cells were determined [130].

7.2. Pili. In addition to the nonflagellated phenotype observed in the $M$. maripaludis acetyltransferase mutant MMP0350, an interesting result was elucidated from this study in relation to the pili in this species [128]. While the cells were typically lacking pili, analysis of the culture supernatants revealed the presence of apparently fully formed pilus structures, suggesting that the glycan defect had not interfered with pili formation but yet had prevented proper attachment of the pili to the cell surface. While this study was interesting in being the first reported case of a gene deletion that resulted in an effect on pili in any archaeal species, it also suggested a more diverse role for the glycan in the surface structures of archaea than previously assumed.

7.3. S Layer. S layer proteins are the other archaeal targets that have proven to be useful reporter proteins for the study of the in vivo function of the N-linked glycan. Mutants producing various truncated glycans have been shown to have altered migration of their corresponding Slayer proteins through SDS-PAGE in both $M$. voltae [18] and $H$. volcanii $[125,126]$. While in $M$. voltae all defects in glycan structure resulted in altered $S$ layer migration in SDSPAGE, in the case of $H$. volcanii, certain deletions of genes confirmed to be involved in the glycosylation pathway did not demonstrate the smaller molecular weight migration that other gene deletions did $[20,127]$. This is somewhat puzzling since only 2 potential sites (at least one is occupied) are found for N-linked glycosylation in M. voltae while 7 (at least 2 of which are used) are found in the S layer protein of H. volcanii. In M. maripaludis, where there is only a single potential $\mathrm{N}$-glycosylation site, no difference in the S layer apparent molecular weight was noticed in glycosylation defective mutants compared to the wild-type, even in an aglB mutant. However, it is not known whether the $\mathrm{N}$-linked sequon actually is occupied in the M. maripaludis $\mathrm{S}$ layer protein.

In both Methanococcus and Haloferax, the S layer is only component of the cell envelope external to the cytoplasmic membrane. Due to the key role of the S layer in these archaea, the specific contribution of glycosylation to the stability and function of the $S$ layer has been addressed extensively in the case of $H$. volcanii and its various $a g l$ mutants.

S-layer proteins in $H$. volcanii strains lacking $\mathrm{AglD}$, the glycosyltransferase responsible for the addition of the terminal sugar, were found to have a defect in the symmetry and the proper assembly of the $S$ layer as compared to wild-type cells [12]. In addition, both AglD mutants and those deficient in $\mathrm{AglB}$, the oligosaccharide transferase, were observed to have substantially deficient growth in media containing higher concentrations of salt compared to those expressing the normal glycan, suggesting a physiological role for the modifications in this halophile. However, analysis of mutants carrying a deletion of a second glycosyltransferase $a g l E$, which is responsible for addition of the second sugar residue, showed no decrease in growth rates at similar salt concentrations [127]. Similar results in which growth rates were unaffected were later reported in mutants carrying deletions in $\operatorname{aglF}$, aglG, and $\operatorname{aglI}[126]$. Another measure of S layer stability tested was the susceptibility of the $S$ layer protein of various $a g l$ mutants to proteases. Interestingly, $S$ layers of cells deleted for aglD were more susceptible to protease treatment than cells deleted for $a g l B$ and thus missing the entire glycan. Mutants carrying deletions of aglM, responsible for addition of the second sugar, had both reduced S layer molecular weight and increased susceptibility to proteases [125]. It has been suggested that N-glycosylation may be an adaptive response in $H$. volcanii since transcription of various $a g l$ genes differs under different growth conditions [125].

\section{Model of Assembly of Archaeal Glycosylated Flagellins into Flagella Filaments}

The N-linked glycosylation system is intimately involved in flagellation in Methanococcus. N-linked glycosylation is one of two major posttranslational modifications that flagellins undergo in $M$. voltae and $M$. maripaludis, the other being signal peptide removal. Like bacterial type IV pilins [45] which form a pilus involved in surface movement called twitching [131], archaeal flagellins are synthesized as preproteins with class III signal peptides [132] that are removed by a dedicated signal peptidase in both systems: PilD in type IV pilus systems [133] and the homologous FlaK/PibD in archaeal flagella systems $[46,47,50]$. Unlike bacterial flagella, the archaeal flagella are not hollow, and there is not a space large enough to accommodate the passage of new subunits to the distal end $[43,44]$. Thus, as was suggested by Jarrell et al. [32], new subunits appear to be incorporated at the base, like pilins.

Both N-linked glycosylation and the signal peptide removal can occur independently of each other. Flagellins are transported to the cytoplasmic membrane, likely guided by chaperones [134], and then undergo glycosylation and processing by the preflagellin peptidase. The posttranslationally modified flagellins are then incorporated at the base of the structure, likely through the activity of FlaI, a homologue of the type IV pilin assembly ATPase PilT [48]. The platform for assembly may be FlaJ, a homologue of the conserved membrane protein PilC in the type IV pilin system [49]. 


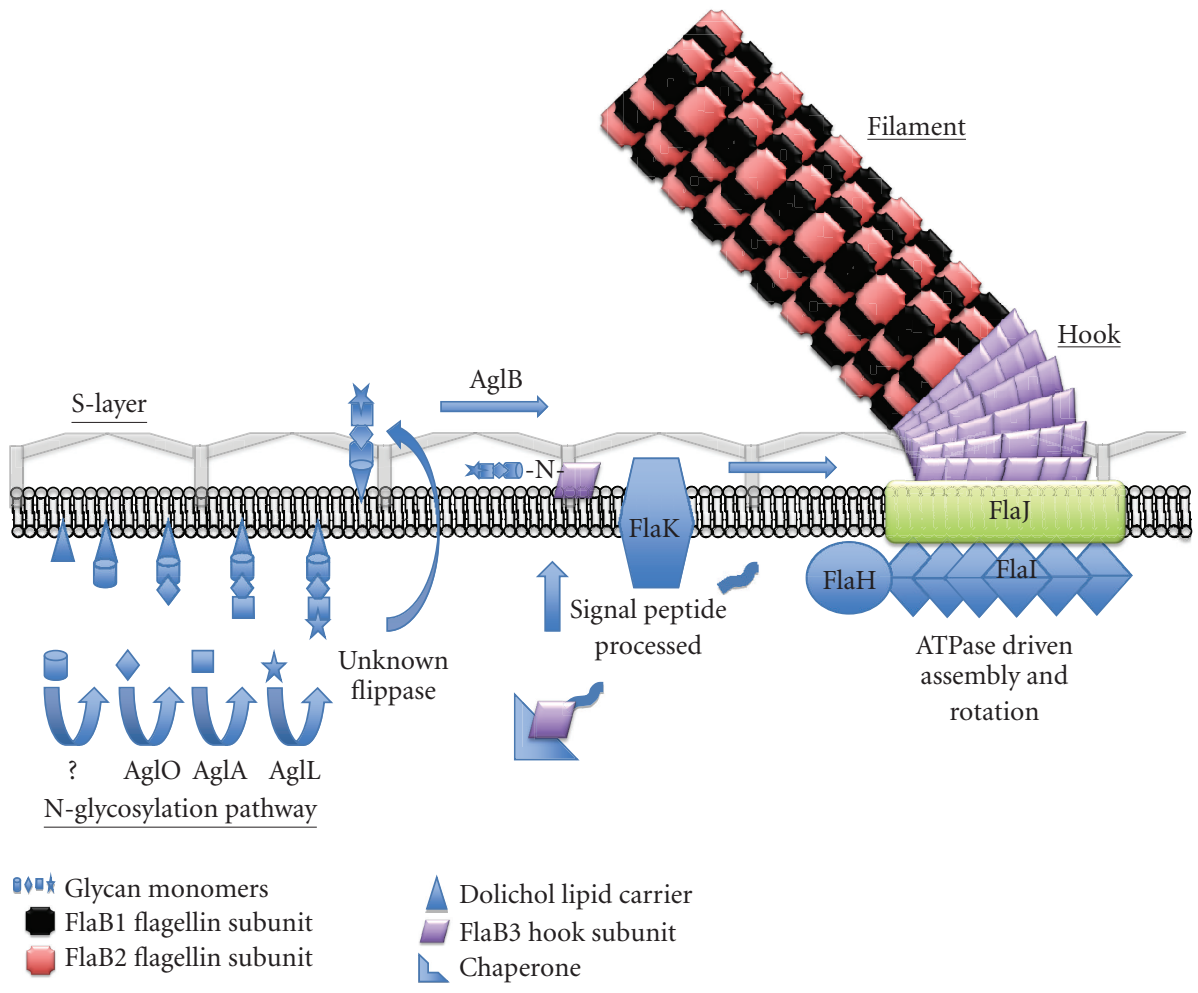

FIGURE 4: Model of assembly of M. maripaludis flagella, incorporating glycan synthesis and signal peptide removal.

A hypothetic model of how the N-linked glycosylation system and assembly of flagellins into flagella are linked is depicted in Figure 4.

Since the S layer protein of $M$. voltae has been shown to be decorated with the same glycan as flagellins and both flagellins and $\mathrm{S}$ layers of $H$. salinarum are decorated with the same $\mathrm{N}$-linked oligosaccharide, it has been assumed that the $\mathrm{N}$-linked system is shared by all glycosylated proteins within a given cell. While this is likely true, there is data already presented in $H$. salinarum that this would be an oversimplification. As pointed out, the $S$ layer protein in this organism has two different $\mathrm{N}$-linked glycans attached at different sequon locations, and only the oligosaccharide glycan is found on flagellins of $H$. salinarum [7], indicating some selectivity in transfer of the glycan even though the transfer is likely to be by a single oligosaccharyltransferase. A novel feature of isolated pili of $M$. maripaludis is that the structural proteins contain a glycan identical to that of the flagellins but with an additional branched hexose attached to the $\mathrm{N}$-acetylgalactosamine (unpublished results).

\section{Conclusions}

$\mathrm{N}$-linked glycosylation in archaea has been demonstrated to occur on a number of proteins, especially those of surface proteins comprising $\mathrm{S}$ layers, flagellins, and pilins. Interference with the $\mathrm{N}$-glycosylation system can have severe effects on flagella assembly and function as well as $\mathrm{S}$ layer stability. Study of N-glycosylation in archaea has shown a wide variety of sugar protein linkages as well as the presence of novel sugar components. These findings have indicated that the archaea are a vast untapped reservoir of biosynthetic and assembly genes for construction of tailored glycoproteins. Even more so than the potential of bacterial glycosylation systems [135], archaeal diversity may have important applications to nanobiotechnology. Since archaeal glycosylation may aid in the stability of proteins in extreme environments $[15,136]$, useful biotechnology applications of these modifications to enhance stability of nonarchaeal proteins under extreme conditions may be possible. It has already been demonstrated that an archaeal glycosyltransferase, that is, $\mathrm{AglH}$, can function effectively in yeast cells [118].

In addition, it has been clearly demonstrated already that study of the archaeal version of this important posttranslational modification can lead to substantial progress in understanding aspects of the eukaryotic version. A case in point is the discovery of an important new motif in the oligosaccharyltransferase of Pyrococcus; subsequent mutational study of the motif in yeast Stt3 revealed its essential role in catalysis [17].

Clearly study of $\mathrm{N}$-glycosylation in Archaea promises to yield exciting findings not only in archaeal physiology but also in eukaryotic biology and biotechnology.

\section{Acknowledgments}

Research conducted in the authors' laboratory was funded by a Discovery Grant and various equipment grants from 
the Natural Sciences and Engineering Research Council of Canada (NSERC).

\section{References}

[1] J. Eichler and M. W. W. Adams, "Posttranslational protein modification in Archaea," Microbiology and Molecular Biology Reviews, vol. 69, no. 3, pp. 393-425, 2005.

[2] C. M. Szymanski and B. W. Wren, "Protein glycosylation in bacterial mucosal pathogens," Nature Reviews Microbiology, vol. 3, no. 3, pp. 225-237, 2005.

[3] M. F. Mescher and J. L. Strominger, "Purification and characterization of a prokaryotic glycoprotein from the cell envelope of Halobacterium salinarium," Journal of Biological Chemistry, vol. 251, no. 7, pp. 2005-2014, 1976.

[4] H. Magidovich and J. Eichler, "Glycosyltransferases and oligosaccharyltransferases in Archaea: putative components of the N-glycosylation pathway in the third domain of life," FEMS Microbiology Letters, vol. 300, no. 1, pp. 122-130, 2009.

[5] P. Messner, "Prokaryotic protein glycosylation is rapidly expanding from "curiosity" to "ubiquity", ChemBioChem, vol. 10, no. 13, pp. 2151-2154, 2009.

[6] C. Schäffer and P. Messner, "Glycobiology of surface layer proteins," Biochimie, vol. 83, no. 7, pp. 591-599, 2001.

[7] M. Sumper, "Halobacterial glycoprotein biosynthesis," Biochimica et Biophysica Acta, vol. 906, no. 1, pp. 69-79, 1987.

[8] U. Karcher, H. Schroder, E. Haslinger et al., "Primary structure of the heterosaccharide of the surface glycoprotein of Methanothermus fervidus," Journal of Biological Chemistry, vol. 268, no. 36, pp. 26821-26826, 1993.

[9] S. Voisin, R. S. Houliston, J. Kelly et al., "Identification and characterization of the unique $\mathrm{N}$-linked glycan common to the flagellins and S-layer glycoprotein of Methanococcus voltae," Journal of Biological Chemistry, vol. 280, no. 17, pp. 16586-16593, 2005.

[10] J. Lechner and M. Sumper, "The primary structure of a procaryotic glycoprotein. Cloning and sequencing of the cell surface glycoprotein gene of halobacteria," Journal of Biological Chemistry, vol. 262, no. 20, pp. 9724-9729, 1987.

[11] R. Mengele and M. Sumper, "Drastic differences in glycosylation of related S-layer glycoproteins from moderate and extreme halophiles," Journal of Biological Chemistry, vol. 267, no. 12, pp. 8182-8185, 1992.

[12] M. Abu-Qarn, S. Yurist-Doutsch, A. Giordano et al., "Haloferax volcanii AglB and AglD are involved in Nglycosylation of the S-layer glycoprotein and proper assembly of the surface layer," Journal of Molecular Biology, vol. 374, no. 5, pp. 1224-1236, 2007.

[13] J. Kelly, S. M. Logan, K. F. Jarrell, D. J. VanDyke, and E. Vinogradov, "A novel N-linked flagellar glycan from Methanococcus maripaludis," Carbohydrate Research, vol. 344, no. 5, pp. 648-653, 2009.

[14] F. Wieland, G. Paul, and M. Sumper, "Halobacterial flagellins are sulfated glycoproteins," Journal of Biological Chemistry, vol. 260, no. 28, pp. 15180-15185, 1985.

[15] U. Zahringer, H. Moll, T. Hettmann, Y. A. Knirel, and G. Schafer, "Cytochrome b558/566 from the archaeon Sulfolobus acidocaldarius has a unique Asn-linked highly branched hexasaccharide chain containing 6-sulfoquinovose," European Journal of Biochemistry, vol. 267, no. 13, pp. 4144-4149, 2000.

[16] L. L. Yang and A. Haug, "Purification and partial characterization of a procaryotic glycoprotein from the plasma membrane of Thermoplasma acidophilum," Biochimica et Biophysica Acta, vol. 556, no. 2, pp. 265-277, 1979.

[17] M. Igura, N. Maita, J. Kamishikiryo et al., "Structure-guided identification of a new catalytic motif of oligosaccharyltransferase," EMBO Journal, vol. 27, no. 1, pp. 234-243, 2008.

[18] B. Chaban, S. Voisin, J. Kelly, S. M. Logan, and K. F. Jarrell, "Identification of genes involved in the biosynthesis and attachment of Methanococcus voltae $\mathrm{N}$-linked glycans: insight into N-linked glycosylation pathways in Archaea," Molecular Microbiology, vol. 61, no. 1, pp. 259-268, 2006.

[19] D. J. Vandyke, J. Wu, S. M. Logan et al., "Identification of genes involved in the assembly and attachment of a novel flagellin N-linked tetrasaccharide important for motility in the archaeon Methanococcus maripaludis," Molecular Microbiology, vol. 72, no. 3, pp. 633-644, 2009.

[20] M. Abu-Qarn and J. Eichler, "Protein N-glycosylation in Archaea: defining Haloferax volcanii genes involved in S-layer glycoprotein glycosylation," Molecular Microbiology, vol. 61, no. 2, pp. 511-525, 2006.

[21] H. J. Doddema, J. W. M. Derksen, and G. D. Vogels, "Fimbriae and flagella of methanogenic bacteria," FEMS Microbiology Letters, vol. 5, no. 3, pp. 135-138, 1979.

[22] R. L. Weiss, "Attachment of bacteria to sulphur in extreme environments," Journal of General Microbiology, vol. 77, no. 2, pp. 501-507, 1973.

[23] S. Y. M. Ng, B. Zolghadr, A. J. M. Driessen, S.-V. Albers, and K. F. Jarrell, "Cell surface structures of archaea," Journal of Bacteriology, vol. 190, no. 18, pp. 6039-6047, 2008.

[24] D. W. Müller, C. Meyer, S. Gürster et al., “The Iho670 fibers of Ignicoccus hospitalis: a new type of archaeal cell surface appendage," Journal of Bacteriology, vol. 191, no. 20, pp. 6465-6468, 2009.

[25] T. Nutsch, D. Oesterhelt, E. D. Gilles, and W. Marwan, "A quantitative model of the switch cycle of an archaeal flagellar motor and its sensory control," Biophysical Journal, vol. 89, no. 4, pp. 2307-2323, 2005.

[26] K. F. Jarrell and M. J. McBride, “The surprisingly diverse ways that prokaryotes move," Nature Reviews Microbiology, vol. 6, no. 6, pp. 466-476, 2008.

[27] S. Y. M. Ng, B. Chaban, and K. F. Jarrell, "Archaeal flagella, bacterial flagella and type IV pili: a comparison of genes and posttranslational modifications," Journal of Molecular Microbiology and Biotechnology, vol. 11, no. 3-5, pp. 167-191, 2006.

[28] S. L. Bardy, S. Y. M. Ng, and K. F. Jarrell, "Recent advances in the structure and assembly of the archaeal flagellum," Journal of Molecular Microbiology and Biotechnology, vol. 7, no. 1-2, pp. 41-51, 2004.

[29] D. M. Faguy and K. F. Jarrell, "A twisted tale: the origin and evolution of motility and chemotaxis in prokaryotes," Microbiology, vol. 145, no. 2, pp. 279-281, 1999.

[30] D. J. Näther, R. Rachel, G. Wanner, and R. Wirth, "Flagella of Pyrococcus furiosus: multifunctional organelles, made for swimming, adhesion to various surfaces, and cell-cell contacts," Journal of Bacteriology, vol. 188, no. 19, pp. 69156923, 2006.

[31] B. Zolghadr, A. Kling, A. Koerdt, A. J.M. Driessen, R. Rachel, and S.-V. Albers, "Appendage-mediated surface adherence of Sulfolobus solfataricus," Journal of Bacteriology, vol. 192, no. 1, pp. 104-110, 2010.

[32] K. F. Jarrell, D. P. Bayley, and A. S. Kostyukova, "The archaeal flagellum: a unique motility structure," Journal of Bacteriology, vol. 178, no. 17, pp. 5057-5064, 1996. 
[33] M. L. Kalmokoff and K. F. Jarrell, "Cloning and sequencing of a multigene family encoding the flagellins of Methanococcus voltae," Journal of Bacteriology, vol. 173, no. 22, pp. 71137125, 1991.

[34] S. L. Bardy, T. Mori, K. Komoriya, S.-I. Aizawa, and K. F. Jarrell, "Identification and localization of flagellins FlaA and FlaB3 within flagella of Methanococcus voltae," Journal of Bacteriology, vol. 184, no. 19, pp. 5223-5233, 2002.

[35] M. Alam and D. Oesterhelt, "Morphology, function and isolation of halobacterial flagella," Journal of Molecular Biology, vol. 176, no. 4, pp. 459-475, 1984.

[36] L. Gerl and M. Sumper, "Halobacterial flagellins are encoded by a multigene family. Characterization of five flagellin genes," Journal of Biological Chemistry, vol. 263, no. 26, pp. 13246-13251, 1988.

[37] L. Gerl, R. Deutzmann, and M. Sumper, "Halobacterial flagellins are encoded by a multigene family. Identification of all five gene products," FEBS Letters, vol. 244, no. 1, pp. 137-140, 1989.

[38] Z. Szabó, M. Sani, M. Groeneveld et al., "Flagellar motility and structure in the hyperthermoacidophilic archaeon Sulfolobus solfataricus," Journal of Bacteriology, vol. 189, no. 11, pp. 4305-4309, 2007.

[39] I. Serganova, V. Ksenzenko, A. Serganov et al., "Sequencing of flagellin genes from Natrialba magadii provides new insight into evolutionary aspects of archaeal flagellins," Journal of Bacteriology, vol. 184, no. 1, pp. 318-322, 2002.

[40] K. Nagahisa, S. Ezaki, S. Fujiwara, T. Imanaka, and M. Takagi, "Sequence and transcriptional studies of five clustered flagellin genes from hyperthermophilic archaeon Pyrococcus kodakaraensis KOD1," FEMS Microbiology Letters, vol. 178, no. 1, pp. 183-190, 1999.

[41] K. F. Jarrell, S. Y. Ng, and B. Chaban, "Flagellation and chemotaxis," in Archaea: Molecular and Cellular Biology, R. Cavicchioli, Ed., pp. 385-410, ASM Press, Washington, DC, USA, 2007.

[42] S. Cohen-Krausz and S. Trachtenberg, "The structure of the archeabacterial flagellar filament of the extreme halophile Halobacterium salinarum R1M1 and its relation to eubacterial flagellar filaments and type IV pili," Journal of Molecular Biology, vol. 321, no. 3, pp. 383-395, 2002.

[43] S. Trachtenberg and S. Cohen-Krausz, "The archaeabacterial flagellar filament: a bacterial propeller with a pilus-like structure," Journal of Molecular Microbiology and Biotechnology, vol. 11, no. 3-5, pp. 208-220, 2006.

[44] S. Cohen-Krausz and S. Trachtenberg, "The flagellar filament structure of the extreme acidothermophile Sulfolobus shibatae B12 suggests that archaeabacterial flagella have a unique and common symmetry and design," Journal of Molecular Biology, vol. 375, no. 4, pp. 1113-1124, 2008.

[45] D. M. Faguy, K. F. Jarrell, J. Kuzio, and M. L. Kalmokoff, "Molecular analysis of archaeal flagellins: similarity to the type IV pilin-transport superfamily widespread in bacteria," Canadian Journal of Microbiology, vol. 40, no. 1, pp. 6771, 1994.

[46] S. L. Bardy and K. F. Jarrell, "FlaK of the archaeon Methanococcus maripaludis possesses preflagellin peptidase activity," FEMS Microbiology Letters, vol. 208, no. 1, pp. 5359, 2002.

[47] S. L. Bardy and K. F. Jarrell, "Cleavage of preflagellins by an aspartic acid signal peptidase is essential for flagellation in the archaeon Methanococcus voltae," Molecular Microbiology, vol. 50, no. 4, pp. 1339-1347, 2003.
[48] D. P. Bayley and K. F. Jarrell, "Further evidence to suggest that archaeal flagella are related to bacterial type IV pili," Journal of Molecular Evolution, vol. 46, no. 3, pp. 370-373, 1998.

[49] C. R. Peabody, Y. J. Chung, M.-R. Yen, D. Vidal-Ingigliardi, A. P. Pugsley, and M. H. Saier Jr., "Type II protein secretion and its relationship to bacterial type IV pili and archaeal flagella," Microbiology, vol. 149, no. 11, pp. 3051-3072, 2003.

[50] S.-V. Albers, Z. Szabó, and A. J. M. Driessen, "Archaeal homolog of bacterial type IV prepilin signal peptidases with broad substrate specificity," Journal of Bacteriology, vol. 185, no. 13, pp. 3918-3925, 2003.

[51] Z. Szabó, S.-V. Albers, and A. J. M. Driessen, "Activesite residues in the type IV prepilin peptidase homologue PibD from the archaeon Sulfolobus solfataricus," Journal of Bacteriology, vol. 188, no. 4, pp. 1437-1443, 2006.

[52] N. Patenge, A. Berendes, H. Engelhardt, S. C. Schuster, and D. Oesterhelt, "The fla gene cluster is involved in the biogenesis of flagella in Halobacterium salinarum," Molecular Microbiology, vol. 41, no. 3, pp. 653-663, 2001.

[53] B. Chaban, S. Y. M. Ng, M. Kanbe et al., "Systematic deletion analyses of the fla genes in the flagella operon identify several genes essential for proper assembly and function of flagella in the archaeon, Methanococcus maripaludis," Molecular Microbiology, vol. 66, no. 3, pp. 596-609, 2007.

[54] N. A. Thomas, C. T. Pawson, and K. F. Jarrell, "Insertional inactivation of the flaH gene in the archaeon Methanococcus voltae results in non-flagellated cells," Molecular Genetics and Genomics, vol. 265, no. 4, pp. 596-603, 2001.

[55] K. F. Jarrell, D. P. Bayley, V. Florian, and A. Klein, "Isolation and characterization of insertional mutations in flagellin genes in the archaeon Methanococcus voltae," Molecular Microbiology, vol. 20, no. 3, pp. 657-666, 1996.

[56] S.-V. Albers and A. J. M. Driessen, "Analysis of ATPases of putative secretion operons in the thermoacidophilic archaeon Sulfolobus solfataricus," Microbiology, vol. 151, no. 3, pp. 763-773, 2005.

[57] A. Yamagata and J. A. Tainer, "Hexameric structures of the archaeal secretion ATPase GspE and implications for a universal secretion mechanism," EMBO Journal, vol. 26, no. 3, pp. 878-890, 2007.

[58] N. A. Thomas and K. F. Jarrell, "Characterization of flagellum gene families of methanogenic archaea and localization of novel flagellum accessory proteins," Journal of Bacteriology, vol. 183, no. 24, pp. 7154-7164, 2001.

[59] S. C. Kachlany, P. J. Planet, R. DeSalle, D. H. Fine, and D. H. Figurski, "Genes for tight adherence of Actinobacillus actinomycetemcomitans: from plaque to plague to pond scum," Trends in Microbiology, vol. 9, no. 9, pp. 429-437, 2001.

[60] S. Streif, W. F. Staudinger, W. Marwan, and D. Oesterhelt, "Flagellar rotation in the archaeon Halobacterium salinarum depends on ATP," Journal of Molecular Biology, vol. 384, no. 1, pp. 1-8, 2008.

[61] R. M. Macnab, "Type III flagellar protein export and flagellar assembly," Biochimica et Biophysica Acta, vol. 1694, no. 1-3, pp. 207-217, 2004.

[62] K. F. Jarrell, D. J. VanDyke, and J. Wu, "Archaeal flagella and pili," in Pili and Flagella: Current Research and Future Trends, K. F. Jarrell, Ed., pp. 215-234, Caister Academic Press, Norfolk, UK, 2009.

[63] S. M. Logan, "Flagellar glycosylation-a new component of the motility repertoire?" Microbiology, vol. 152, no. 5, pp. 1249-1262, 2006. 
[64] B. Chaban, S. M. Logan, J. F. Kelly, and K. F. Jarrell, "AglC and $\mathrm{AglK}$ are involved in biosynthesis and attachment of diacetylated glucuronic acid to the N-glycan in Methanococcus voltae," Journal of Bacteriology, vol. 91, no. 1, pp. 187-195, 2009.

[65] C. Thoma, M. Frank, R. Rachel et al., "The Mth60 fimbriae of Methanothermobacter thermoautotrophicus are functional adhesins," Environmental Microbiology, vol. 10, no. 10, pp. 2785-2795, 2008.

[66] S. Fröls, P. M. K. Gordon, M. A. Panlilio et al., "Response of the hyperthermophilic archaeon Sulfolobus solfataricus to UV damage," Journal of Bacteriology, vol. 189, no. 23, pp. 8708 8718, 2007.

[67] S. Fröls, M. Ajon, M. Wagner et al., "UV-inducible cellular aggregation of the hyperthermophilic archaeon Sulfolobus solfataricus is mediated by pili formation," Molecular Microbiology, vol. 70, no. 4, pp. 938-952, 2008.

[68] Y. A. Wang, X. Yu, S. Y. M. Ng, K. F. Jarrell, and E. H. Egelman, "The structure of an archaeal pilus," Journal of Molecular Biology, vol. 381, no. 2, pp. 456-466, 2008.

[69] Z. Szabó, A. O. Stahl, S.-V. Albers, J. C. Kissinger, A. J. M. Driessen, and M. Pohlschröder, "Identification of diverse archaeal proteins with class III signal peptides cleaved by distinct archaeal prepilin peptidases," Journal of Bacteriology, vol. 189, no. 3, pp. 772-778, 2007.

[70] S. Y. M. Ng, D. J. VanDyke, B. Chaban et al., "Different minimal signal peptide lengths recognized by the archaeal prepilin-like peptidases FlaK and PibD," Journal of Bacteriology, vol. 191, no. 21, pp. 6732-6740, 2009.

[71] G. Rieger, R. Rachel, R. Hermann, and K. O. Stetter, "Ultrastructure of the hyperthermophilic archaeon Pyrodictium abyssi," Journal of Structural Biology, vol. 115, no. 1, pp. 7887, 1995.

[72] S. Nickell, R. Hegerl, W. Baumeister, and R. Rachel, "Pyrodictium cannulae enter the periplasmic space but do not enter the cytoplasm, as revealed by cryo-electron tomography," Journal of Structural Biology, vol. 141, no. 1, pp. 34-42, 2003.

[73] C. Moissl, R. Rachel, A. Briegel, H. Engelhardt, and R. Huber, "The unique structure of archaeal 'hami', highly complex cell appendages with nano-grappling hooks," Molecular Microbiology, vol. 56, no. 2, pp. 361-370, 2005.

[74] R. Henneberger, C. Moissl, T. Amann, C. Rudolph, and R. Huber, "New insights into the lifestyle of the cold-loving SM1 euryarchaeon: natural growth as a monospecies biofilm in the subsurface," Applied and Environmental Microbiology, vol. 72, no. 1, pp. 192-199, 2006.

[75] S.-V. Albers and M. Pohlschröder, "Diversity of archaeal type IV pilin-like structures," Extremophiles, vol. 13, no. 3, pp. 403-410, 2009.

[76] S.-V. Albers, Z. Szabó, and A. J. M. Driessen, "Protein secretion in the Archaea: multiple paths towards a unique cell surface," Nature Reviews Microbiology, vol. 4, no. 7, pp. 537$547,2006$.

[77] M. G. L. Elferink, S.-V. Albers, W. N. Konings, and A. J. M. Driessen, "Sugar transport in Sulfolobus solfataricus is mediated by two families of binding protein-dependent $\mathrm{ABC}$ transporters," Molecular Microbiology, vol. 39, no. 6, pp. 1494-1503, 2001.

[78] B. Zolghadr, S. Weber, Z. Szabó, A. J. M. Driessen, and S.-V. Albers, "Identification of a system required for the functional surface localization of sugar binding proteins with class III signal peptides in Sulfolobus solfataricus," Molecular Microbiology, vol. 64, no. 3, pp. 795-806, 2007.
[79] M. L. Kalmokoff, S. F. Koval, and K. F. Jarrell, "Relatedness of the flagellins from methanogens," Archives of Microbiology, vol. 157, no. 6, pp. 481-487, 1992.

[80] H. Claus, E. Akça, T. Debaerdemaeker et al., "Molecular organization of selected prokaryotic S-layer proteins," Canadian Journal of Microbiology, vol. 51, no. 9, pp. 731-743, 2005.

[81] H. Engelhardt, "Are S-layers exoskeletons? The basic function of protein surface layers revisited," Journal of Structural Biology, vol. 160, no. 2, pp. 115-124, 2007.

[82] P. Messner, "Bacterial glycoproteins," Glycoconjugate Journal, vol. 14, no. 1, pp. 3-11, 1997.

[83] P. Messner, G. Allmaier, C. Schäffer et al., "Biochemistry of S-layers," FEMS Microbiology Reviews, vol. 20, no. 1-2, pp. 25-46, 1997.

[84] U. B. Sleytr and T. J. Beveridge, "Bacterial S-layers," Trends in Microbiology, vol. 7, no. 6, pp. 253-260, 1999.

[85] R. K. Upreti, M. Kumar, and V. Shankar, "Bacterial glycoproteins: functions, biosynthesis and applications," Proteomics, vol. 3, no. 4, pp. 363-379, 2003.

[86] D. Pum, P. Messner, and U. B. Sleytr, "Role of the S layer in morphogenesis and cell division of the archaebacterium Methanocorpusculum sinense," Journal of Bacteriology, vol. 173, no. 21, pp. 6865-6873, 1991.

[87] M. Sára and U. B. Sleytr, "S-layer proteins," Journal of Bacteriology, vol. 182, no. 4, pp. 859-868, 2000.

[88] B. M. Phipps, R. Huber, and W. Baumeister, "The cell envelope of the hyperthermophilic archaebacterium Pyrobaculum organotrophum consists of two regularly arrayed protein layers: three-dimensional structure of the outer layer," Molecular Microbiology, vol. 5, no. 2, pp. 253-265, 1991.

[89] M. Wacker, D. Linton, P. G. Hitchen et al., "N-linked glycosylation in Campylobacter jejuni and its functional transfer into E. coli," Science, vol. 298, no. 5599, pp. 17901793, 2002.

[90] H. Nothaft, X. Liu, D. J. McNally, and C. M. Szymanski, "Nlinked protein glycosylation in a bacterial system," Methods in Molecular Biology, vol. 600, pp. 227-243, 2010.

[91] N. Maita, J. Nyirenda, M. Igura, J. Kamishikiryo, and D. Kohda, "Comparative structural biology of eubacterial and archaeal oligosaccharyltransferases," Journal of Biological Chemistry, vol. 285, no. 7, pp. 4941-4950, 2010.

[92] D. Linton, N. Dorrell, P. G. Hitchen et al., "Functional analysis of the Campylobacter jejuni N-linked protein glycosylation pathway," Molecular Microbiology, vol. 55, no. 6, pp. 16951703, 2005.

[93] J. Lechner, F. Wieland, and M. Sumper, "Biosynthesis of sulfated saccharides $\mathrm{N}$-glycosidically linked to the protein via glucose. Purification and identification of sulfated dolichyl monophosphoryl tetrasaccharides from halobacteria," Journal of Biological Chemistry, vol. 260, no. 2, pp. 860-866, 1985.

[94] C. Kuntz, J. Sonnenbichler, I. Sonnenbichler, M. Sumper, and R. Zeitler, "Isolation and characterization of dolichol-linked oligoscaccharides from Haloferax volcanii," Glycobiology, vol. 7, no. 7, pp. 897-904, 1997.

[95] E. Weerapana and B. Imperiali, "Asparagine-linked protein glycosylation: from eukaryotic to prokaryotic systems," Glycobiology, vol. 16, no. 6, pp. 91R-101R, 2006.

[96] J. Lechner and F. Wieland, "Structure and biosynthesis of prokaryotic glycoproteins," Annual Review of Biochemistry, vol. 58, pp. 173-194, 1989.

[97] J. Kelly, H. Jarrell, L. Millar et al., "Biosynthesis of the Nlinked glycan in Campylobacter jejuni and addition onto protein through block transfer," Journal of Bacteriology, vol. 188, no. 7, pp. 2427-2434, 2006. 
[98] J. Helenius, D. T. W. Ng, C. L. Marolda, P. Walter, M. A. Valvano, and M. Aebi, "Translocation of lipid-linked oligosaccharides across the ER membrane requires $\mathrm{Rft} 1$ protein," Nature, vol. 415, no. 6870, pp. 447-450, 2002.

[99] C. G. Frank, S. Sanyal, J. S. Rush, C. J. Waechter, and A. K. Menon, "Does Rft1 flip an N-glycan lipid precursor?" Nature, vol. 454, no. 7204, pp. E3-E4, 2008.

[100] N. Plavner and J. Eichler, "Defining the topology of the Nglycosylation pathway in the halophilic archaeon Haloferax volcanii," Journal of Bacteriology, vol. 190, no. 24, pp. 80458052, 2008.

[101] N. M. Young, J.-R. Brisson, J. Kelly et al., "Structure of the $\mathrm{N}$-linked glycan present on multiple glycoproteins in the gram-negative bacterium, Campylobacter jejuni," Journal of Biological Chemistry, vol. 277, no. 45, pp. 42530-42539, 2002.

[102] P. Messner and U. B. Sleytr, "Asparaginyl-rhamnose: a novel type of protein-carbohydrate linkage in a eubacterial surfacelayer glycoprotein," FEBS Letters, vol. 228, no. 2, pp. 317-320, 1988.

[103] C. Schäffer, T. Wugeditsch, H. Kählig, A. Scheberl, S. Zayni, and P. Messner, "The surface layer (S-layer) glycoprotein of Geobacillus stearothermophilus NRS 2004/3a. Analysis of its glycosylation," Journal of Biological Chemistry, vol. 277, no. 8, pp. 6230-6239, 2002.

[104] R. Schreiner, E. Schnabel, and F. Wieland, "Novel Nglycosylation in eukaryotes: laminin contains the linkage unit $\beta$ - glucosylasparagine," Journal of Cell Biology, vol. 124, no. 6, pp. 1071-1081, 1994.

[105] F. Wieland, R. Heitzer, and W. Schaefer, "Asparaginylglucose: novel type of carbohydrate linkage," Proceedings of the National Academy of Sciences of the United States of America, vol. 80, no. 181, pp. 5470-5474, 1983.

[106] M. Abu-Qarn, J. Eichler, and N. Sharon, "Not just for Eukarya anymore: protein glycosylation in Bacteria and Archaea," Current Opinion in Structural Biology, vol. 18, no. 5, pp. 544-550, 2008.

[107] M. Wacker, M. F. Feldman, N. Callewaert et al., "Substrate specificity of bacterial oligosaccharyltransferase suggests a common transfer mechanism for the bacterial and eukaryotic systems," Proceedings of the National Academy of Sciences of the United States of America, vol. 103, no. 18, pp. 7088-7093, 2006.

[108] V. W.-F. Tai and B. Imperiali, "Substrate specificity of the glycosyl donor for oligosaccharyl transferase," Journal of Organic Chemistry, vol. 66, no. 19, pp. 6217-6228, 2001.

[109] M. F. Feldman, M. Wacker, M. Hernandez et al., "Engineering $\mathrm{N}$-linked protein glycosylation with diverse $\mathrm{O}$ antigen lipopolysaccharide structures in Escherichia coli," Proceedings of the National Academy of Sciences of the United States of America, vol. 102, no. 8, pp. 3016-3021, 2005.

[110] D. Karaoglu, D. J. Kelleher, and R. Gilmore, "Allosteric regulation provides a molecular mechanism for preferential utilization of the fully assembled dolichol-linked oligosaccharide by the yeast oligosaccharyltransferase," Biochemistry, vol. 40, no. 40, pp. 12193-12206, 2001.

[111] P. Burda and M. Aebi, "The ALG10 locus of Saccharomyces cerevisiae encodes the $\alpha-1,2$ glucosyltransferase of the endoplasmic reticulum: the terminal glucose of the lipid-link oligosaccharide is required for efficient $\mathrm{N}$-linked glycosylation," Glycobiology, vol. 8, no. 5, pp. 455-462, 1998.

[112] M. Nita-Lazar, M. Wacker, B. Schegg, S. Amber, and M. Aebi, "The N-X-S/T consensus sequence is required but not sufficient for bacterial N-linked protein glycosylation," Glycobiology, vol. 15, no. 4, pp. 361-367, 2005.
[113] M. Abu-Qarn and J. Eichler, "An analysis of amino acid sequences surrounding archaeal glycoprotein sequons," Archaea, vol. 2, no. 2, pp. 73-81, 2007.

[114] R. Zeitler, E. Hochmuth, R. Deutzmann, and M. Sumper, "Exchange of Ser-4 for Val, Leu or Asn in the sequon AsnAla-Ser does not prevent N-glycosylation of the cell surface glycoprotein from Halobacterium halobium," Glycobiology, vol. 8, no. 12, pp. 1157-1164, 1998.

[115] H. Magidovich, S. Yurist-Doutsch, Z. Konrad et al., "AglP is a $\mathrm{S}$-adenosyl-L-methionine-dependent methyltransferase that participates in the $\mathrm{N}$-glycosylation pathway of Haloferax volcanii," Molecular Microbiology, vol. 76, no. 1, pp. 190-199, 2010.

[116] M. Sumper and F. T. Wieland, "Bacterial glycoproteins," in Glycoproteins, J. Montreuil, J. F. G. Vliegenthart, and H. Schachter, Eds., pp. 455-473, Elsevier, Amsterdam, The Netherlands, 1995.

[117] P. Pellerin, B. Fournet, and P. Debeire, "Evidence for the glycoprotein nature of the cell sheath of Methanosaeta-like cells in the culture of Methanothrix soehngenii strain FE," Canadian Journal of Microbiology, vol. 36, no. 9, pp. 631-636, 1990.

[118] H. Shams-Eldin, B. Chaban, S. Niehus, R. T. Schwarz, and K. F. Jarrell, "Identification of the archaeal alg7 gene homolog (encoding $\mathrm{N}$-acetylglucosamine-1-phosphate transferase) of the N-linked glycosylation system by cross-domain complementation in Saccharomyces cerevisiae," Journal of Bacteriology, vol. 190, no. 6, pp. 2217-2220, 2008.

[119] S. C. Namboori and D. E. Graham, "Acetamido sugar biosynthesis in the euryarchaea," Journal of Bacteriology, vol. 190, no. 8, pp. 2987-2996, 2008.

[120] F. D. Sauer, B. A. Blackwell, J. K. G. Kramer, and B. J. Marsden, "Structure of novel cofactor containing N-(7mercaptoheptanoyl)-O-3-phosphothreonine," Biochemistry, vol. 29, no. 33, pp. 7593-7600, 1990.

[121] B. C. Moore and J. A. Leigh, "Markerless mutagenesis in Methanococcus maripaludis demonstrates roles for alanine dehydrogenase, alanine racemase, and alanine permease," Journal of Bacteriology, vol. 187, no. 3, pp. 972-979, 2005.

[122] J. S. Rush, C. Alaimo, R. Robbiani, M. Wacker, and C. J. Waechter, "A novel epimerase that converts GlcNAc-P-Pundecaprenol to GalNAc-P-P-undecaprenol in Escherichia coli O1570," Journal of Biological Chemistry, vol. 285, no. 3, pp. 1671-1680, 2010.

[123] G. Ferrante, I. Ekiel, and G. D. Sprott, "Structural characterization of the lipids of Methanococcus voltae, including a novel N-acetylglucosamine 1-phosphate diether," Journal of Biological Chemistry, vol. 261, no. 36, pp. 17062-17066, 1986.

[124] S. Yurist-Doutsch and J. Eichler, "Manual annotation, transcriptional analysis, and protein expression studies reveal novel genes in the $a g l$ cluster responsible for $\mathrm{N}$ glycosylation in the halophilic archaeon Haloferax volcanii," Journal of Bacteriology, vol. 191, no. 9, pp. 3068-3075, 2009.

[125] S. Yurist-Doutsch, H. Magidovich, V. V. Ventura, P. G. Hitchen, A. Dell, and J. Eichler, "N-glycosylation in Archaea: on the coordinated actions of Haloferax volcanii AglF and AglM," Molecular Microbiology, vol. 75, no. 4, pp. 1047-1058, 2010.

[126] S. Yurist-Doutsch, M. Abu-Qarn, F. Battaglia et al., "AglF, aglG and aglI, novel members of a gene island involved in the N-glycosylation of the Haloferax volcanii S-layer glycoprotein," Molecular Microbiology, vol. 69, no. 5, pp. 1234-1245, 2008. 
[127] M. Abu-Qarn, A. Giordano, F. Battaglia et al., "Identification of AglE, a second glycosyltransferase involved in N glycosylation of the Haloferax volcanii S-layer glycoprotein," Journal of Bacteriology, vol. 190, no. 9, pp. 3140-3146, 2008.

[128] D. J. VanDyke, J. Wu, S. Y. M. Ng et al., "Identification of a putative acetyltransferase gene, MMP0350, which affects proper assembly of both flagella and pili in the archaeon Methanococcus maripaludis," Journal of Bacteriology, vol. 190, no. 15, pp. 5300-5307, 2008.

[129] M. Igura, N. Maita, T. Obita, J. Kamishikiryo, K. Maenaka, and D. Kohda, "Purification, crystallization and preliminary X-ray diffraction studies of the soluble domain of the oligosaccharyltransferase STT3 subunit from the thermophilic archaeon Pyrococcus furiosus," Acta Crystallographica F, vol. 63, no. 9, pp. 798-801, 2007.

[130] D. P. Bayley, M. L. Kalmokoff, and K. F. Jarrell, "Effect of bacitracin on flagellar assembly and presumed glycosylation of the flagellins of Methanococcus deltae," Archives of Microbiology, vol. 160, no. 3, pp. 179-185, 1993.

[131] D. E. Bradley, "A function of Pseudomonas aeruginosa PAO polar pili: twitching motility," Canadian Journal of Microbiology, vol. 26, no. 2, pp. 146-154, 1980.

[132] M. Pohlschröder, M. I. Giménez, and K. F. Jarrell, "Protein transport in Archaea: sec and twin arginine translocation pathways," Current Opinion in Microbiology, vol. 8, no. 6, pp. 713-719, 2005.

[133] M. S. Strom, D. N. Nunn, and S. Lory, "Posttranslational processing of type IV prepilin and homologs by PilD of Pseudomonas aeruginosa," Methods in Enzymology, vol. 235, pp. 527-540, 1994.

[134] Y. Y. Polosina, K. F. Jarrell, O. V. Fedorov, and A. S. Kostyukova, "Nucleoside diphosphate kinase from haloalkaliphilic archaeon Natronobacterium magadii: purification and characterization," Extremophiles, vol. 2, no. 3, pp. 333338, 1998.

[135] C. Schäffer and P. Messner, "Surface-layer glycoproteins: an example for the diversity of bacterial glycosylation with promising impacts on nanobiotechnology," Glycobiology, vol. 14, no. 8, pp. 31R-42R, 2004.

[136] S. Yurist-Doutsch, B. Chaban, D. J. VanDyke, K. F. Jarrell, and J. Eichler, "Sweet to the extreme: protein glycosylation in Archaea," Molecular Microbiology, vol. 68, no. 5, pp. 10791084, 2008. 

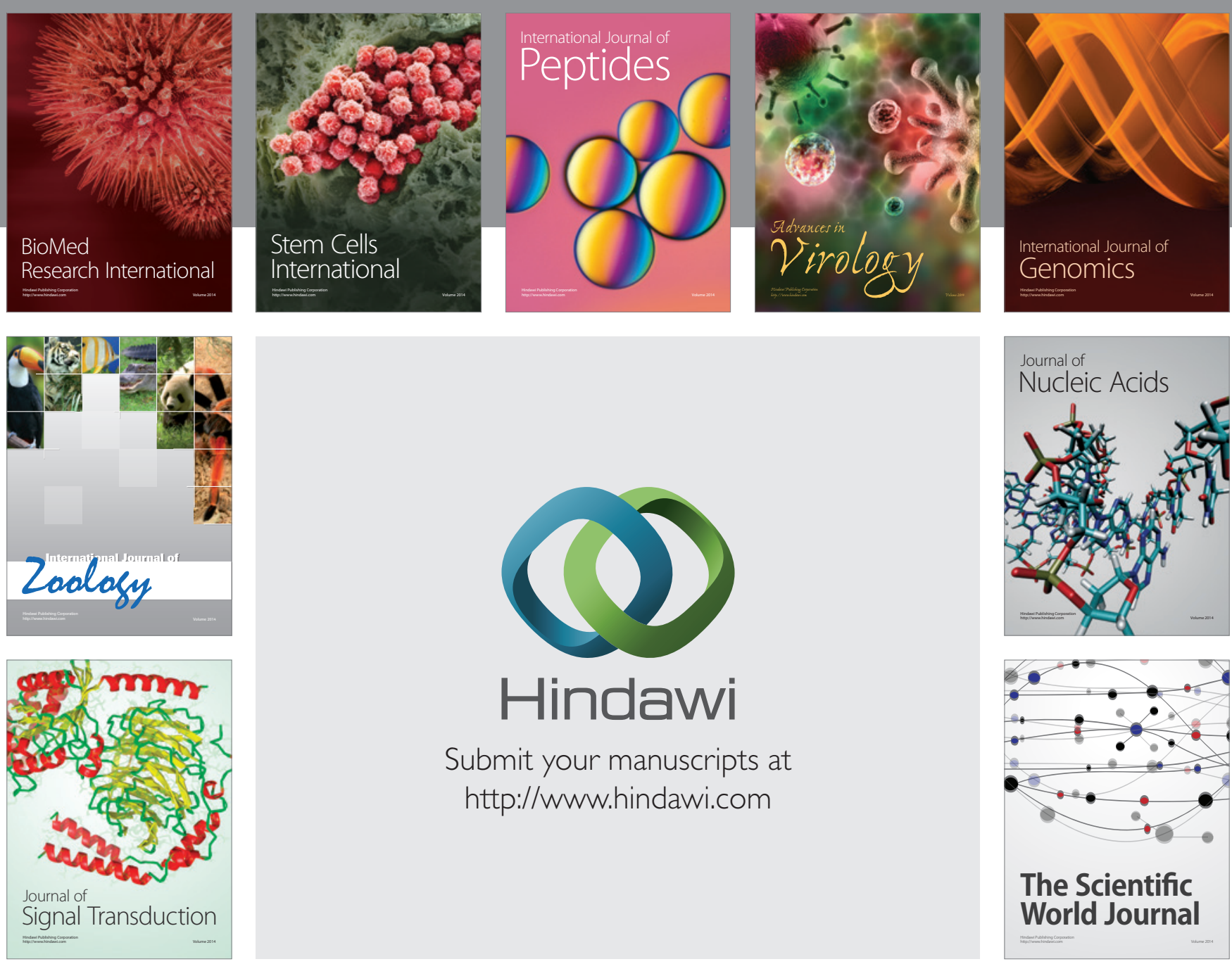

Submit your manuscripts at

http://www.hindawi.com
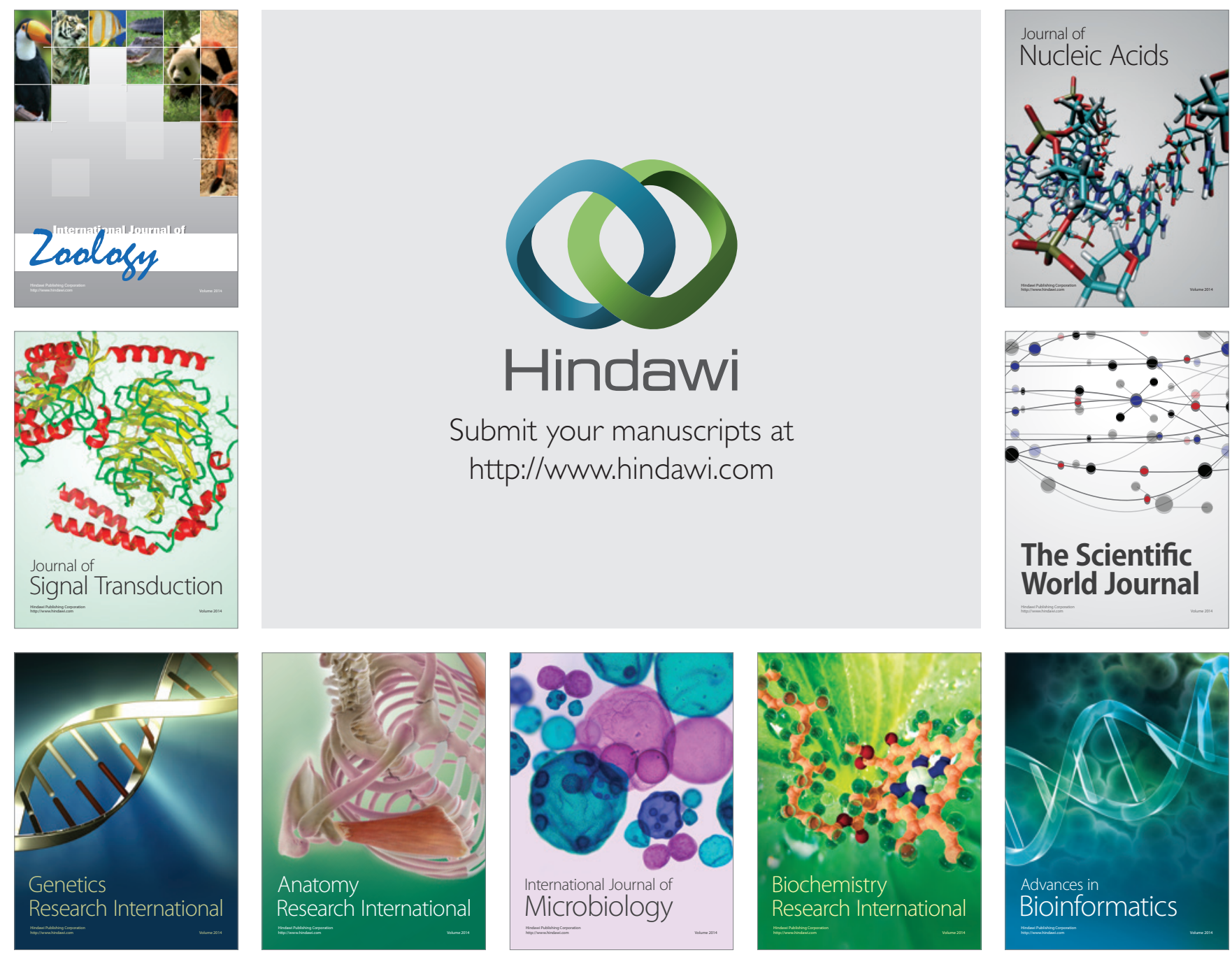

The Scientific World Journal
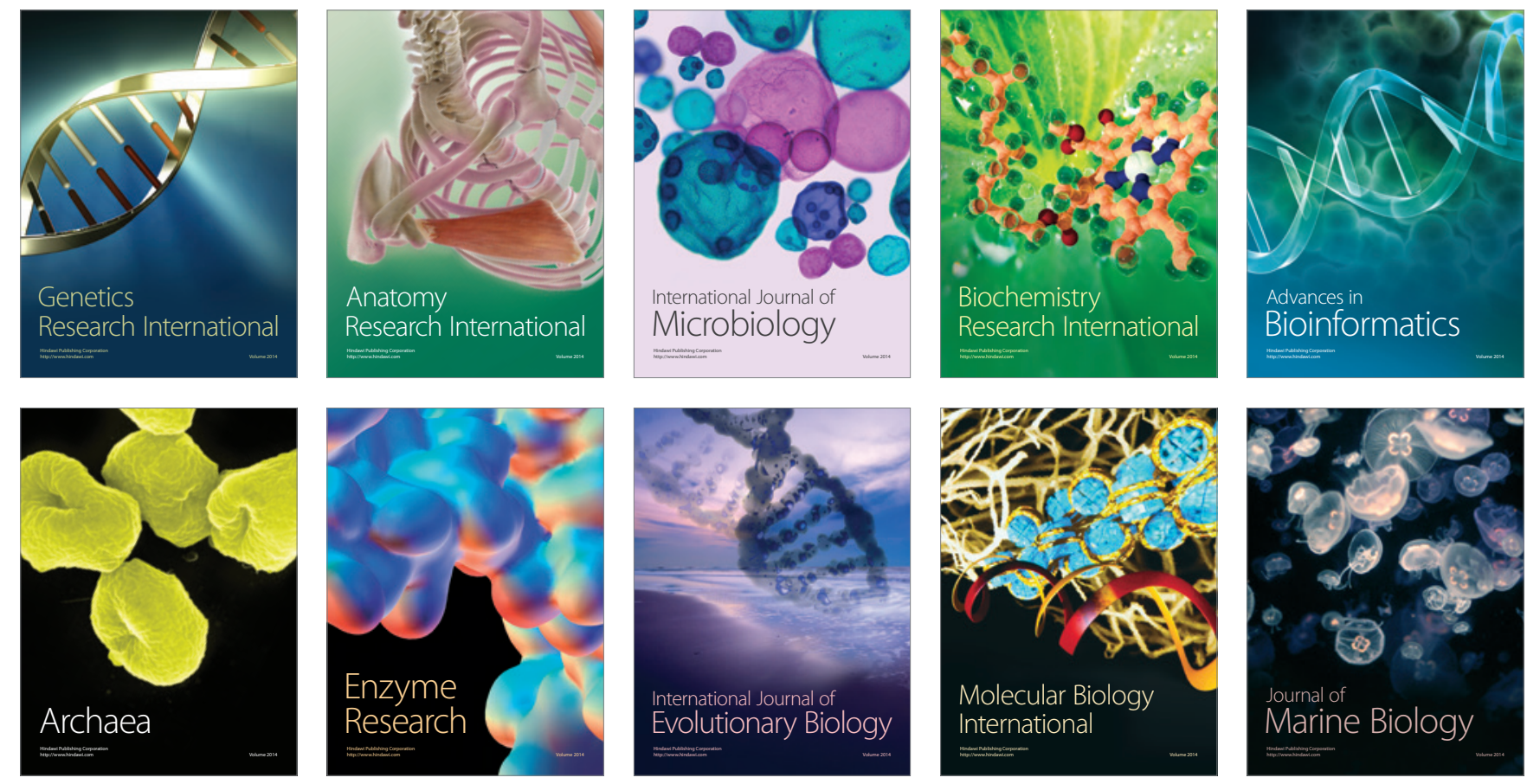